\title{
Big GABA
}

Citation for published version (APA):

Mikkelsen, M., Barker, P. B., Bhattacharyya, P. K., Brix, M. K., Buur, P. F., Cecil, K. M., Chan, K. L., Chen, D. Y. -T., Craven, A. R., Cuypers, K., Dacko, M., Duncan, N. W., Dydak, U., Edmondson, D. A., Ende, G., Ersland, L., Gao, F., Greenhouse, I., Harris, A. D., ... Edden, R. A. E. (2017). Big GABA: Edited MR spectroscopy at 24 research sites. Neuroimage, 159, 32-45.

https://doi.org/10.1016/j.neuroimage.2017.07.021

Document status and date:

Published: 01/10/2017

DOI:

10.1016/j.neuroimage.2017.07.021

Document Version:

Publisher's PDF, also known as Version of record

\section{Document license:}

Taverne

\section{Please check the document version of this publication:}

- A submitted manuscript is the version of the article upon submission and before peer-review. There can be important differences between the submitted version and the official published version of record.

People interested in the research are advised to contact the author for the final version of the publication, or visit the DOI to the publisher's website.

- The final author version and the galley proof are versions of the publication after peer review.

- The final published version features the final layout of the paper including the volume, issue and page numbers.

Link to publication

\footnotetext{
General rights rights.

- You may freely distribute the URL identifying the publication in the public portal. please follow below link for the End User Agreement:

www.umlib.nl/taverne-license

Take down policy

If you believe that this document breaches copyright please contact us at:

repository@maastrichtuniversity.nl

providing details and we will investigate your claim.
}

Copyright and moral rights for the publications made accessible in the public portal are retained by the authors and/or other copyright owners and it is a condition of accessing publications that users recognise and abide by the legal requirements associated with these

- Users may download and print one copy of any publication from the public portal for the purpose of private study or research.

- You may not further distribute the material or use it for any profit-making activity or commercial gain

If the publication is distributed under the terms of Article $25 \mathrm{fa}$ of the Dutch Copyright Act, indicated by the "Taverne" license above, 


\section{Big GABA: Edited MR spectroscopy at 24 research sites}

Mark Mikkelsen $^{\text {a,b }}$, Peter B. Barker ${ }^{\mathrm{a}, \mathrm{b}}$, Pallab K. Bhattacharyya ${ }^{\mathrm{c}, \mathrm{d}}$, Maiken K. Brix ${ }^{\mathrm{e}, \mathrm{f}}$, Pieter F. Buur ${ }^{g}$, Kim M. Cecil ${ }^{\text {h }}$, Kimberly L. Chan ${ }^{\text {a,b,i }}$, David Y.-T. Chen ${ }^{j}$, Alexander R. Craven ${ }^{\text {k, },}$, Koen Cuypers ${ }^{\mathrm{m}, \mathrm{n}}$, Michael Dacko ${ }^{\circ}$, Niall W. Duncan ${ }^{\mathrm{p}}$, Ulrike Dydak ${ }^{\mathrm{q}}$, David A. Edmondson ${ }^{\mathrm{q}}$, Gabriele Ende $^{\mathrm{r}}$, Lars Ersland ${ }^{\mathrm{k}, 1, \mathrm{~s}}$, Fei Gao ${ }^{\mathrm{t}}$, Ian Greenhouse ${ }^{\mathrm{u}}$, Ashley D. Harris ${ }^{\mathrm{v}}$, Naying He ${ }^{\mathrm{w}}$, Stefanie Heba ${ }^{\mathrm{x}}$, Nigel Hoggard ${ }^{\mathrm{y}}$, Tun-Wei Hsu ${ }^{\mathrm{z}}$, Jacobus F.A. Jansen ${ }^{\text {aa }}$, Alayar Kangarlu ${ }^{\text {ab, ac }}$, Thomas Lange $^{\circ}$, R. Marc Lebel ${ }^{\text {ad }}$, Yan Li ${ }^{w}$, Chien-Yuan E. Lin ${ }^{\text {ae }}$, Jy-Kang Liou ${ }^{z}$, Jiing-Feng Lirng ${ }^{\mathrm{z}}$, Feng Liu ${ }^{\mathrm{ac}}$, Ruoyun Ma ${ }^{\mathrm{q}}$, Celine Maes ${ }^{\mathrm{m}}$, Marta Moreno-Ortega ${ }^{\mathrm{ab}}$, Scott O. Murray ${ }^{\text {af }}$, Sean Noah ${ }^{\mathrm{u}}$, Ralph Noeske ${ }^{\mathrm{ag}}$, Michael D. Noseworthy ${ }^{\text {ah }}$, Georg Oeltzschner $^{\mathrm{a}, \mathrm{b}}$, James J. Prisciandaro ${ }^{\text {ai }}$, Nicolaas A.J. Puts ${ }^{\mathrm{a}, \mathrm{b}}$, Timothy P.L. Roberts ${ }^{\text {aj }}$, Markus Sack $^{\mathrm{r}}$, Napapon Sailasuta ${ }^{\mathrm{ak}, \mathrm{al}}$, Muhammad G. Saleh ${ }^{\mathrm{a}, \mathrm{b}}$, Michael-Paul Schallmo ${ }^{\text {af }}$, Nicholas Simard ${ }^{\mathrm{am}}$, Stephan P. Swinnen ${ }^{\mathrm{m} \text {, an }}$, Martin Tegenthoff ${ }^{\mathrm{x}}$, Peter Truong ${ }^{\mathrm{ak}}$, Guangbin Wang ${ }^{\mathrm{t}}$, Iain D. Wilkinson ${ }^{\mathrm{y}}$, Hans-Jörg Wittsack ${ }^{\mathrm{ao}}$, Hongmin $\mathrm{Xu}^{\mathrm{w}}$, Fuhua Yan ${ }^{\mathrm{w}}$, Chencheng Zhang ${ }^{\text {ap }}$, Vadim Zipunnikov ${ }^{\text {aq }}$, Helge J. Zöllner ${ }^{\text {ao,ar }}$, Richard A.E. Edden ${ }^{\text {a,b,* }}$

${ }^{a}$ Russell H. Morgan Department of Radiology and Radiological Science, The Johns Hopkins University School of Medicine, Baltimore, MD, USA

${ }^{\mathrm{b}}$ F. M. Kirby Research Center for Functional Brain Imaging, Kennedy Krieger Institute, Baltimore, MD, USA

${ }^{\mathrm{c}}$ Imaging Institute, Cleveland Clinic Foundation, Cleveland, OH, USA

${ }^{\mathrm{d}}$ Radiology, Cleveland Clinic Lerner College of Medicine of Case Western Reserve University, Cleveland, OH, USA

e Department of Radiology, Haukeland University Hospital, Bergen, Norway

${ }^{\mathrm{f}}$ Department of Clinical Medicine, University of Bergen, Bergen, Norway

${ }^{g}$ Spinoza Centre for Neuroimaging, Amsterdam, The Netherlands

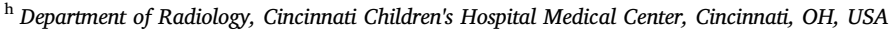

i Department of Biomedical Engineering, The Johns Hopkins University School of Medicine, Baltimore, MD, USA

${ }^{j}$ Department of Radiology, Taipei Medical University Shuang Ho Hospital, New Taipei City, Taiwan

${ }^{\mathrm{k}}$ Department of Biological and Medical Psychology, University of Bergen, Bergen, Norway

${ }^{1}$ NORMENT - Norwegian Center for Mental Disorders Research, University of Bergen, Bergen, Norway

${ }^{\mathrm{m}}$ Department of Kinesiology, KU Leuven, Leuven, Belgium

${ }^{\mathrm{n}}$ REVAL Rehabilitation Research Center, Hasselt University, Diepenbeek, Belgium

${ }^{\circ}$ Department of Radiology, Medical Physics, Medical Center - University of Freiburg, Faculty of Medicine, Freiburg, Germany

${ }^{\mathrm{p}}$ Brain and Consciousness Research Centre, Taipei Medical University, Taipei, Taiwan

${ }^{\mathrm{q}}$ School of Health Sciences, Purdue University, West Lafayette, IN, USA

${ }^{\mathrm{r}}$ Department of Neuroimaging, Central Institute of Mental Health, Mannheim, Germany

s Department of Clinical Engineering, Haukeland University Hospital, Bergen, Norway

${ }^{t}$ Shandong Medical Imaging Research Institute, Shandong University, Jinan, China

${ }^{\mathrm{u}}$ Helen Wills Neuroscience Institute, University of California, Berkeley, Berkeley, CA, USA

${ }^{\mathrm{v}}$ Department of Radiology, University of Calgary, Calgary, AB, Canada

${ }^{\mathrm{w}}$ Department of Radiology, Ruijin Hospital, Shanghai Jiao Tong University School of Medicine, Shanghai, China

${ }^{\mathrm{x}}$ Department of Neurology, BG University Hospital Bergmannsheil, Bochum, Germany

${ }^{\mathrm{y}}$ Academic Unit of Radiology, University of Sheffield, Sheffield, UK

${ }^{\mathrm{z}}$ Department of Radiology, Taipei Veterans General Hospital, National Yang-Ming University School of Medicine, Taipei, Taiwan

${ }^{\text {aa }}$ Department of Radiology, Maastricht University Medical Center, Maastricht, The Netherlands

${ }^{\mathrm{ab}}$ Department of Psychiatry, Columbia University, New York, NY, USA

${ }^{\text {ac }}$ New York State Psychiatric Institute, New York, NY, USA

${ }^{\text {ad }}$ GE Healthcare, Calgary, AB, Canada

ae GE Healthcare, Taipei, Taiwan

${ }^{\text {af }}$ Department of Psychology, University of Washington, Seattle, WA, USA

${ }^{\text {ag }}$ GE Healthcare, Berlin, Germany

\footnotetext{
* Corresponding author. Division of Neuroradiology, Park 367H, The Johns Hopkins University School of Medicine, 600 N Wolfe St, Baltimore, MD 21287, USA.
} 
${ }^{\text {ah }}$ Department of Electrical and Computer Engineering, McMaster University, Hamilton, ON, Canada

ai Department of Psychiatry and Behavioral Sciences, Medical University of South Carolina, Charleston, SC, USA

aj Department of Radiology, Children's Hospital of Philadelphia, Philadelphia, PA, USA

${ }^{\mathrm{ak}}$ Research Imaging Centre, Centre for Addiction and Mental Health, Toronto, ON, Canada

${ }^{\text {al }}$ Department of Psychiatry, University of Toronto, Toronto, ON, Canada

${ }^{a m}$ School of Biomedical Engineering, McMaster University, Hamilton, ON, Canada

${ }^{\text {an }}$ Leuven Research Institute for Neuroscience \& Disease (LIND), KU Leuven, Leuven, Belgium

${ }^{\text {ao }}$ Department of Diagnostic and Interventional Radiology, Medical Faculty, Heinrich-Heine-University, Duesseldorf, Germany

${ }^{a p}$ Department of Functional Neurosurgery, Ruijin Hospital, Shanghai Jiao Tong University School of Medicine, Shanghai, China

${ }^{\mathrm{aq}}$ Department of Biostatistics, Johns Hopkins Bloomberg School of Public Health, Baltimore, MD, USA

${ }^{\mathrm{ar}}$ Institute of Clinical Neuroscience and Medical Psychology, Medical Faculty, Heinrich-Heine-University, Duesseldorf, Germany

\section{A R T I C L E I N F O}

\section{Keywords:}

Editing

GABA

MEGA-PRESS

MRS

Multi-site study

\begin{abstract}
A B S T R A T
Magnetic resonance spectroscopy (MRS) is the only biomedical imaging method that can noninvasively detect endogenous signals from the neurotransmitter $\gamma$-aminobutyric acid (GABA) in the human brain. Its increasing popularity has been aided by improvements in scanner hardware and acquisition methodology, as well as by broader access to pulse sequences that can selectively detect GABA, in particular $J$-difference spectral editing sequences. Nevertheless, implementations of GABA-edited MRS remain diverse across research sites, making comparisons between studies challenging. This large-scale multi-vendor, multi-site study seeks to better understand the factors that impact measurement outcomes of GABA-edited MRS. An international consortium of 24 research sites was formed. Data from 272 healthy adults were acquired on scanners from the three major MRI vendors and analyzed using the Gannet processing pipeline. MRS data were acquired in the medial parietal lobe with standard GABA + and macromolecule- (MM-) suppressed GABA editing. The coefficient of variation across the entire cohort was $12 \%$ for GABA+ measurements and $28 \%$ for MM-suppressed GABA measurements. A multilevel analysis revealed that most of the variance (72\%) in the GABA+ data was accounted for by differences between participants within-site, while site-level differences accounted for comparatively more variance (20\%) than vendor-level differences (8\%). For MM-suppressed GABA data, the variance was distributed equally between site- $(50 \%)$ and participant-level (50\%) differences. The findings show that GABA+ measurements exhibit strong agreement when implemented with a standard protocol. There is, however, increased variability for MMsuppressed GABA measurements that is attributed in part to differences in site-to-site data acquisition. This study's protocol establishes a framework for future methodological standardization of GABA-edited MRS, while the results provide valuable benchmarks for the MRS community.
\end{abstract}

\section{Introduction}

Magnetic resonance spectroscopy (MRS) is unique amongst the neuroimaging modalities in detecting endogenous signals from complex molecules in the brain noninvasively. Of particular interest is the detection and measurement of $\gamma$-aminobutyric acid (GABA), the major inhibitory neurotransmitter in the mammalian brain (McCormick, 1989). Healthy brain function relies on GABAergic inhibitory processes, and understanding GABAergic mechanisms in both healthy and pathological brain function has been one core focus of neuroscience. MRS measurements of GABA have been associated with individual differences in hemodynamic and electrophysiological signals (Donahue et al., 2010; Hu et al., 2013; Kapogiannis et al., 2013; Muthukumaraswamy et al., 2009) and a number of measures of cognition (Fujihara et al., 2015; Shibata et al., 2017; Yoon et al., 2016) and behavior (Boy et al., 2011; Greenhouse et al., 2017; Puts et al., 2011; Silveri et al., 2013). Differential levels of GABA have been observed in a number of neuropsychiatric disorders, such as schizophrenia (Kegeles et al., 2012; Öngür et al., 2010; Rowland et al., 2016; Yoon et al., 2010) and depression (Bhagwagar et al., 2008; Hasler et al., 2007; Price et al., 2009), neurodevelopmental disorders, such as autism spectrum disorder (Drenthen et al., 2016; Gaetz et al., 2014; Puts et al., 2016) and attention deficit hyperactivity disorder (Bollmann et al., 2015; Edden et al., 2012a), and neurological diseases, such as Parkinson's disease (Emir et al., 2012), amyotrophic lateral sclerosis (Foerster et al., 2012, 2013) and diabetic neuropathy (Petrou et al., 2012).

The most common MRS approach for detecting the GABA signal is the Mescher-Garwood (MEGA) editing sequence (Mescher et al., 1998), a $J$ difference spectral editing technique that is typically implemented within a point resolved spectroscopy (PRESS) (Bottomley, 1987) acquisition. MEGA-PRESS and other spectral editing techniques exploit the known scalar coupling properties of molecules in order to separate their associated signals from the overlapping signals of other molecules. For lower-concentration metabolites such as GABA, spectral editing differentiates the weak signals of interest from the stronger, overlapping signals of higher-concentration metabolites. Difference editing techniques in particular use frequency-selective inversion pulses to achieve this (for methodological reviews, see Harris et al., 2017; Puts and Edden, 2012). The popularity of MEGA-PRESS is attributed to a number of factors, including the wide availability of the basic PRESS sequence across scanner platforms, its relatively straightforward implementation (Mullins et al., 2014), its reproducibility (Bogner et al., 2010; Brix et al., 2017; Geramita et al., 2011; Mikkelsen et al., 2016a; Near et al., 2014; O'Gorman et al., 2011; Shungu et al., 2016) and continued development of acquisition methodology and data processing tools (Chan et al., 2016; Edden et al., 2014).

However, despite these positive attributes, the diversity of implementations of MEGA-PRESS across research sites and vendors has meant that comparing data between different studies is difficult. For instance, pulse sequence parameters, and in particular pulse timings, differ between vendor-specific PRESS sequences and lead to subtle but important differences in the resolved GABA signal (Near et al., 2013b). Moreover, spectral editing of GABA is associated with a number of complexities, including TE-dependent $J$-evolution of the GABA spin system (Edden et al., 2012b), frequency and spatial effects of volume localization (Edden and Barker, 2007; Kaiser et al., 2008), sensitivity to $B_{0}$ field frequency offsets (Edden et al., 2016; Harris et al., 2014) and contamination from co-edited macromolecules (MM) (Henry et al., 2001; Rothman et al., 1993). It is generally assumed that these factors limit the degree to which a GABA-edited measurement from one site can be compared to another at a different site.

In order to establish the extent to which site-, sequence- and vendorspecific differences impact quantitative MEGA-PRESS measurement 
outcomes, a multi-vendor, multi-site dataset has been assembled by an international consortium of GABA-edited MRS users. The consortium was formed with the aim of building a normative database of MEGA-PRESS data acquired on the major MRI scanner platforms at a range of imaging centers focused on neuroscience research. This dataset aims to capture some of the diversity of the sequences used, but within the framework of a standardized study design and acquisition protocol that would reflect typical MEGA-PRESS parameters. This approach reduced the number of confounding variables present within the dataset (e.g., standardizing key parameters such as TE, TR and editing pulse bandwidth), while maintaining diversity at the level of pulse sequence implementation (e.g., localization pulse waveforms/bandwidths, pulse timings and crusher gradient schemes).

This paper presents initial results from this multi-site study, focusing on how variance in creatine-referenced GABA measurements was distributed across research sites and scanner vendors and examining the influence of various acquisition- and participant-related effects. Given the complexity of this dataset, it is not possible to report on all aspects of the project in a single article, so for example, water-referenced quantification (including tissue-dependent correction factors) and site-to-site differences in voxel placement fidelity and segmentation will be presented in a future report.

\section{Methods}

\subsection{Data collection}

A consortium of 24 research institutions based in nine countries participated in this initiative, with each site contributing 5-12 datasets collected from consenting adult volunteers. Specific guidelines for each site's participant cohort were: 18-35 years old; approximately 50:50 female/male split; no known neurological or psychiatric illness. In total, data from 272 participants were collected. Participant demographics are provided in Table 1. Scanning was conducted in accordance with ethical standards set by the institutional review board (IRB) at each site, including the sharing of anonymized data. Anonymized data files were shared securely with and analyzed by consortium members at the Johns Hopkins University School of Medicine with local IRB approval.

Table 1

Participant demographics, displayed by site and by vendor.

\begin{tabular}{|c|c|c|c|}
\hline Site ID & Sample size & Age (years) $($ mean $\pm S D)$ & $\operatorname{Sex}(F / M)$ \\
\hline G1 & 12 & $23.92 \pm 4.81$ & $7 / 5$ \\
\hline G2 & 12 & $26.83 \pm 4.00$ & $6 / 6$ \\
\hline G3 & 7 & $23.43 \pm 5.47$ & $2 / 5$ \\
\hline G4 & 12 & $25.58 \pm 4.48$ & $6 / 6$ \\
\hline G5 & 12 & $25.50 \pm 3.73$ & $5 / 7$ \\
\hline G6 & 12 & $24.33 \pm 4.25$ & $6 / 6$ \\
\hline G7 & 12 & $28.08 \pm 4.01$ & $6 / 6$ \\
\hline G8 & 12 & $29.67 \pm 2.10$ & $6 / 6$ \\
\hline All GE & 91 & $26.05 \pm 4.43$ & $44 / 47$ \\
\hline $\mathrm{P} 1$ & 12 & $25.08 \pm 3.23$ & $6 / 6$ \\
\hline $\mathrm{P} 2$ & 12 & $28.75 \pm 3.91$ & $10 / 2$ \\
\hline P3 & 12 & $29.25 \pm 3.14$ & $5 / 7$ \\
\hline P4 & 12 & $24.92 \pm 4.29$ & $7 / 5$ \\
\hline P5 & 8 & $23.13 \pm 2.36$ & $3 / 5$ \\
\hline P6 & 12 & $27.33 \pm 3.68$ & $7 / 5$ \\
\hline P7 & 12 & $23.58 \pm 3.73$ & $6 / 6$ \\
\hline P8 & 12 & $23.25 \pm 1.96$ & $5 / 7$ \\
\hline P9 & 12 & $25.83 \pm 4.61$ & $6 / 6$ \\
\hline All Philips & 104 & $25.78 \pm 4.06$ & $55 / 49$ \\
\hline S1 & 12 & $25.67 \pm 3.65$ & $6 / 6$ \\
\hline S2 & 5 & $40.40 \pm 7.44$ & $0 / 5$ \\
\hline S3 & 12 & $31.58 \pm 3.42$ & $9 / 3$ \\
\hline S4 & 12 & $27.67 \pm 2.77$ & $6 / 6$ \\
\hline S5 & 12 & $26.50 \pm 3.68$ & $6 / 6$ \\
\hline S6 & 12 & $24.92 \pm 2.02$ & $6 / 6$ \\
\hline S7 & 12 & $28.75 \pm 3.77$ & $6 / 6$ \\
\hline All Siemens & 77 & $28.35 \pm 5.21$ & $39 / 38$ \\
\hline Overall & 272 & $26.60 \pm 4.65$ & $138 / 134$ \\
\hline
\end{tabular}

\subsection{Data acquisition}

Each site acquired MEGA-PRESS data on a $3 \mathrm{~T}$ scanner by following a standard scan protocol as closely as possible. Eight sites used GE scanners, nine used Philips scanners and seven used Siemens scanners, with locally available phased-array head coils (see Table 2). Two MRS acquisitions were run: a standard GABA+-edited acquisition where ON editing pulses were placed at $1.9 \mathrm{ppm}$ and OFF editing pulses were placed at $7.46 \mathrm{ppm}$; and an MM-suppressed GABA-edited acquisition where the editing pulses were placed symmetrically about the MM resonance at $1.7 \mathrm{ppm}(\mathrm{ON} / \mathrm{OFF}=1.9 / 1.5 \mathrm{ppm})$ (Henry et al., 2001). GE site 6 (G6) did not acquire MM-suppressed data. For the sequences used in this study, GE and Philips editing pulse offsets are calculated assuming a water frequency of $4.68 \mathrm{ppm}$ and Siemens assumes $4.7 \mathrm{ppm}$. Given that GABA editing involves the use of frequency-selective editing pulses, their inversion frequency bandwidth has a significant impact on editing efficiency, determining the extent of MM co-editing in GABA+ acquisitions and the extent of GABA nulling in symmetric MM suppression (see Edden et al., 2016; Harris et al., 2014; Terpstra et al., 2002). For GE and Philips implementations where editing pulse duration is specified, editing pulse duration was set to $15 \mathrm{~ms}$ for the GABA+ acquisition and $20 \mathrm{~ms}$ for the MM-suppressed GABA acquisition. This equated to inversion bandwidths at full-width half-maximum (FWHM) of $81.7 / 82.5 \mathrm{~Hz}$ (GE/Philips) for the GABA+ acquisition and 61.3/61.9 Hz (GE/Philips) for the MMsuppressed GABA acquisition. For Siemens implementations, where the editing pulse bandwidth specified on the scanner does not correspond to the FWHM bandwidth (Lange et al., 2016), FWHM bandwidths were $82.4 \mathrm{~Hz}$ for the GABA+ acquisition and $61.8 \mathrm{~Hz}$ for the MM-suppressed GABA acquisition. The TE of the GABA+ acquisition was set to $68 \mathrm{~ms}$. For the MM-suppressed acquisition, the TE was set to $80 \mathrm{~ms}$ on the GE and Philips platforms (Edden et al., 2012c) and to $68 \mathrm{~ms}$ on the Siemens platform. The higher peak $B_{1}$ on some Siemens platforms makes the more selective editing pulses possible without increasing the TE. For one Siemens site (S2), the TE of the MM-suppressed acquisition was increased to $80 \mathrm{~ms}$ due to limited peak $B_{1}$. Representative vendor-specific MEGAPRESS pulse sequence diagrams (at TE $=68 \mathrm{~ms}$ ) are shown in Fig. 1A. Parameters common between the two acquisitions included: $\mathrm{TR}=2000 \mathrm{~ms} ; 320$ averages (i.e., $160 \mathrm{ON}$ and $160 \mathrm{OFF}$ transients); $\sim 10$ min scan time. Although the spectral width and number of discrete data points differed from site to site (see Table 2), in all cases the aim was to achieve a data acquisition time of $\sim 1 \mathrm{~s}$. All Philips sites except P8 addressed $B_{0}$ field offsets with prospective frequency correction based on interleaved water referencing (Edden et al., 2016). Specifically, for every 40 water-suppressed acquisitions, a water-unsuppressed acquisition was performed and used to correct the center frequency in real-time. This method was only available on the Philips platform at the time of data collection. Details of $B_{0}$ shimming approaches are provided in Table 2. All three vendors use a volume-localized acquisition for center frequency calibration. They differ somewhat in terms of localization method (e.g., STEAM on Siemens and semi-LASER on Philips) and acquisition resolution; both GE and Philips suppress fat signals to make algorithmic determination of center frequency more robust. GE data were saved in Pfile format, Philips data were saved in SDAT/SPAR format and Siemens data were saved in TWIX format.

All MEGA-PRESS data were acquired from a $30 \times 30 \times 30 \mathrm{~mm}^{3}$ voxel placed in the medial parietal lobe (Fig. 1B). All sites followed the same protocol, using a guideline image, for voxel placement. Briefly, the voxel was rotated in the sagittal plane to align it with a line connecting the genu and splenium of the corpus callosum. Each site was instructed to comply with the standardized protocol, but also to avoid ventricles and/ or the outer surfaces of the brain when necessary to ensure good data quality.

\subsection{Data processing}

Data from each site were processed in Gannet (Edden et al., 2014) 
Table 2

Software, hardware and acquisition parameters used to collect MEGA-PRESS data at each site.

\begin{tabular}{|c|c|c|c|c|c|c|c|c|c|c|c|c|}
\hline Site ID & $\begin{array}{l}\text { Scanner vendor } \\
\text { and model }\end{array}$ & $\begin{array}{l}\text { Software } \\
\text { release }\end{array}$ & Tx/Rx hardware & $\begin{array}{l}B_{0} \text { shimming } \\
\text { approach }\end{array}$ & $\begin{array}{l}\text { MEGA-PRESS } \\
\text { sequence } \\
\text { variant }\end{array}$ & $\begin{array}{l}\text { Phase } \\
\text { cycling }\end{array}$ & $\begin{array}{l}\text { Editing } \\
\text { interleaving }\end{array}$ & $\begin{array}{l}\text { TE (ms) } \\
(\mathrm{GABA}+)\end{array}$ & $\begin{array}{l}\text { TE (ms) } \\
\text { (MM-s GABA) }\end{array}$ & $\begin{array}{l}\text { Spectral } \\
\text { width }(\mathrm{Hz})\end{array}$ & $\begin{array}{l}\text { Data } \\
\text { points }\end{array}$ & $\begin{array}{l}\text { Water } \\
\text { suppression }\end{array}$ \\
\hline G1 & $\begin{array}{l}\text { GE Discovery } \\
\text { MR750w }\end{array}$ & DV25 & $\begin{array}{l}\text { Body coil/32-ch } \\
\text { head coil }\end{array}$ & $\begin{array}{l}\text { Double-echo } \\
\text { GRE }\end{array}$ & $\begin{array}{l}\text { Interleaved } \\
\text { sequence }^{\mathrm{a}}\end{array}$ & 2 steps & 2 TRs & 68 & 80 & 5000 & 4096 & CHESS \\
\hline G2 & $\begin{array}{l}\text { GE Discovery } \\
\text { MR750 }\end{array}$ & DV24 & $\begin{array}{l}\text { Body coil/8-ch } \\
\text { head coil }\end{array}$ & $\begin{array}{l}\text { Double-echo } \\
\text { GRE }\end{array}$ & ATSM patch ${ }^{\mathrm{b}}$ & 2 steps & $1 \mathrm{TR}$ & 68 & 80 & 2000 & 2048 & CHESS \\
\hline G3 & $\begin{array}{l}\text { GE Discovery } \\
\text { MR750 }\end{array}$ & DV24 & $\begin{array}{l}\text { Body coil/32-ch } \\
\text { head coil }\end{array}$ & $\begin{array}{l}\text { Double-echo } \\
\text { GRE }\end{array}$ & ATSM patch & 8 steps & $1 \mathrm{TR}$ & 68 & 80 & 2000 & 2048 & CHESS \\
\hline G4 & $\begin{array}{l}\text { GE Discovery } \\
\text { MR750 }\end{array}$ & DV25 & $\begin{array}{l}\text { Body coil/8-ch } \\
\text { head coil }\end{array}$ & $\begin{array}{l}\text { Double-echo } \\
\text { GRE }\end{array}$ & ATSM patch & 8 steps & $1 \mathrm{TR}$ & 68 & 80 & 5000 & 4096 & CHESS \\
\hline G5 & $\begin{array}{l}\text { GE Discovery } \\
\text { MR750 }\end{array}$ & DV25 & $\begin{array}{l}\text { Body coil/32-ch } \\
\text { head coil }\end{array}$ & $\begin{array}{l}\text { Double-echo } \\
\text { GRE }\end{array}$ & ATSM patch & 8 steps & $1 \mathrm{TR}$ & 68 & 80 & 2000 & 2048 & CHESS \\
\hline G6 & GE Signa HDx & HD16 & $\begin{array}{l}\text { Body coil/8-ch } \\
\text { head coil }\end{array}$ & $\begin{array}{l}\text { Double-echo } \\
\text { GRE }\end{array}$ & ATSM patch & 2 steps & 2 TRs & 68 & - & 2000 & 2048 & CHESS \\
\hline G7 & $\begin{array}{l}\text { GE Discovery } \\
\text { MR750 }\end{array}$ & DV24 & $\begin{array}{l}\text { Body coil/8-ch } \\
\text { head coil }\end{array}$ & $\begin{array}{l}\text { Double-echo } \\
\text { GRE }\end{array}$ & ATSM patch & 8 steps & $1 \mathrm{TR}$ & 68 & 80 & 2000 & 2048 & CHESS \\
\hline G8 & $\begin{array}{l}\text { GE Discovery } \\
\text { MR750 }\end{array}$ & DV24 & $\begin{array}{l}\text { Body coil/8-ch } \\
\text { head coil }\end{array}$ & $\begin{array}{l}\text { Double-echo } \\
\text { GRE }\end{array}$ & ATSM patch & 8 steps & $1 \mathrm{TR}$ & 68 & 80 & 2000 & 2048 & CHESS \\
\hline P1 & Philips Achieva & R5.1.7 & $\begin{array}{l}\text { Body coil/32-ch } \\
\text { head coil }\end{array}$ & PB-auto ${ }^{c}$ & JHU patch ${ }^{\mathrm{d}}$ & 16 steps & $1 \mathrm{TR}$ & 68 & 80 & 2000 & 2048 & VAPOR \\
\hline P2 & Philips Achieva & R5.1.7 & $\begin{array}{l}\text { Body coil/32-ch } \\
\text { head coil }\end{array}$ & PB-auto & JHU patch & 16 steps & $1 \mathrm{TR}$ & 68 & 80 & 2000 & 2048 & VAPOR \\
\hline P3 & Philips Achieva & R3.2.2 & $\begin{array}{l}\text { Body coil/32-ch } \\
\text { head coil }\end{array}$ & PB-auto & JHU patch & 16 steps & $1 \mathrm{TR}$ & 68 & 80 & 2000 & 2048 & VAPOR \\
\hline P4 & $\begin{array}{l}\text { Philips Ingenia } \\
\text { CX }\end{array}$ & R5.1.7 & $\begin{array}{l}\text { Body coil/32-ch } \\
\text { head coil }\end{array}$ & PB-auto & JHU patch & 16 steps & $1 \mathrm{TR}$ & 68 & 80 & 2000 & 2048 & MOIST \\
\hline P5 & $\begin{array}{l}\text { Philips Achieva } \\
\text { TX }\end{array}$ & R5.1.7 & $\begin{array}{l}\text { Body coil/32-ch } \\
\text { head coil }\end{array}$ & PB-auto & JHU patch & 16 steps & $1 \mathrm{TR}$ & 68 & 80 & 2000 & 2048 & MOIST \\
\hline P6 & Philips Achieva & R3.2.3 & $\begin{array}{l}\text { Body coil/8-ch } \\
\text { head coil }\end{array}$ & PB-auto & JHU patch & 16 steps & $1 \mathrm{TR}$ & 68 & 80 & 2000 & 2048 & MOIST \\
\hline P7 & Philips Ingenia & R5.1.8 & $\begin{array}{l}\text { Body coil/32-ch } \\
\text { head coil }\end{array}$ & PB-auto & JHU patch & 16 steps & $1 \mathrm{TR}$ & 68 & 80 & 2000 & 2048 & VAPOR \\
\hline P8 & $\begin{array}{l}\text { Philips Ingenia } \\
\text { CX }\end{array}$ & R5.1.8 & $\begin{array}{l}\text { Body coil/32-ch } \\
\text { head coil }\end{array}$ & PB-auto & JHU patch ${ }^{\mathrm{e}}$ & 16 steps & $1 \mathrm{TR}$ & 68 & 80 & 2000 & 2048 & MOIST \\
\hline P9 & Philips Achieva & R5.1.7 & $\begin{array}{l}\text { Body coil/32-ch } \\
\text { head coil }\end{array}$ & PB-auto & JHU patch & 16 steps & $1 \mathrm{TR}$ & 68 & 80 & 2000 & 2048 & VAPOR \\
\hline S1 & Siemens Trio & VB17 & $\begin{array}{l}\text { Body coil/32-ch } \\
\text { head coil }\end{array}$ & $\begin{array}{l}\text { 3D-DESS + } \\
\text { manual }\end{array}$ & WIP (529) & 16 steps & $1 \mathrm{TR}$ & 68 & 68 & $4000^{f}$ & 4096 & CHESS \\
\hline S2 & Siemens Verio & VB17 & $\begin{array}{l}\text { Body coil/32-ch } \\
\text { head coil }\end{array}$ & $\begin{array}{l}\text { 3D-DESS + } \\
\text { manual }\end{array}$ & WIP (529) & 16 steps & $1 \mathrm{TR}$ & 68 & 80 & 4000 & 4096 & CHESS \\
\hline S3 & Siemens Prisma & VD13 & $\begin{array}{l}\text { Body coil/20-ch } \\
\text { head/neck coil }\end{array}$ & $\begin{array}{l}\text { FAST(EST) } \\
\text { MAP }\end{array}$ & WIP (859D) & 16 steps & $1 \mathrm{TR}$ & 68 & 68 & 4000 & 4096 & WET \\
\hline S4 & Siemens Prisma & VE11 & $\begin{array}{l}\text { Body coil/64-ch } \\
\text { head coil }\end{array}$ & 3D-DESS & $\begin{array}{l}\text { WIP (user- } \\
\text { modified) }\end{array}$ & 16 steps & $1 \mathrm{TR}$ & 68 & 68 & 4000 & 4096 & WET \\
\hline S5 & Siemens Trio & VB17 & $\begin{array}{l}\text { Body coil/12-ch } \\
\text { head coil }\end{array}$ & 3D-DESS & WIP (529) & 16 steps & $1 \mathrm{TR}$ & 68 & 68 & 4000 & 4096 & CHESS \\
\hline S6 & Siemens Trio & VB17 & $\begin{array}{l}\text { Body coil/32-ch } \\
\text { head coil }\end{array}$ & $\begin{array}{l}\text { FAST(EST) } \\
\text { MAP }\end{array}$ & WIP (529) & 16 steps & $1 \mathrm{TR}$ & 68 & 68 & 4000 & 4096 & WET \\
\hline S7 & Siemens Trio & VB17 & $\begin{array}{l}\text { Body coil/32-ch } \\
\text { head coil }\end{array}$ & $\begin{array}{l}\text { FAST(EST) } \\
\text { MAP }\end{array}$ & $\begin{array}{l}\text { WIP (user- } \\
\text { modified) }\end{array}$ & 16 steps & $1 \mathrm{TR}$ & 68 & 68 & 2000 & $\begin{array}{l}2070 / \\
2080^{g}\end{array}$ & CHESS \\
\hline
\end{tabular}

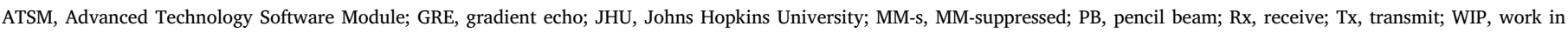
progress.

${ }^{a}$ Sequence developed by Gareth Barker, David Lythgoe (King's College London), C. John Evans (Cardiff University) and RAEE; originally based on Dikoma Shungu's sequence (Weill Cornell Medical College).

b Including source code derivatives. Sequence developed by RN.

c PB-auto is a Philips pencil-beam projection-based method for automatic voxel shimming.

d Sequence developed by RAEE.

e Interleaved water referencing not implemented.

f TWIX data are oversampled. For example, if the specified spectral width and number of discrete data points are set at $2000 \mathrm{~Hz} / 2048$, the data are oversampled to $4000 \mathrm{~Hz} / 4096$.

$\mathrm{g}$ In the Siemens WIP, extra data points are added before and/or after the detected spin echo if the number of data points is specified as 512 or 1024 . The additional points before the spin

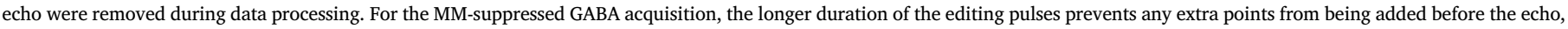
hence the difference in the number of data points between the two acquisitions for site S7.

using the software's automated analysis pipeline with some in-house customization for this study. Raw time-domain data were first corrected for frequency and phase errors by spectral registration (Near et al., 2015) using the transient $10 \%$ into the acquisition (i.e., the 32nd transient) as a reference. ON/OFF transient pairs were rejected from further processing if either of their corresponding frequency/phase offset estimates were greater than 3 standard deviations (SDs) from the mean of frequency/phase offset estimates for all pre-corrected transients. A threshold of 3 SDs corresponds to $99.7 \%$ of (normally distributed) frequency/phase estimates. ON/OFF transient pairs exceeding this threshold would be expected to introduce more uncertainty into the data (Waddell et al., 2007) and were therefore removed. The data were then filtered using a 3-Hz exponential weighting function and zero-filled so as to yield a nominal spectral resolution of $0.061 \mathrm{~Hz} /$ point upon fast Fourier transformation. Individual $\mathrm{ON}$ and OFF subspectra were then averaged and subtracted to produce the edited difference (DIFF) spectrum.

Data were visually inspected for spectral artifacts, specifically lipid contamination, subtraction errors and a non-constant baseline. Individual datasets were rejected if the signal fitting routine (details below) was compromised. For instance, significant lipid contamination can distort 
A

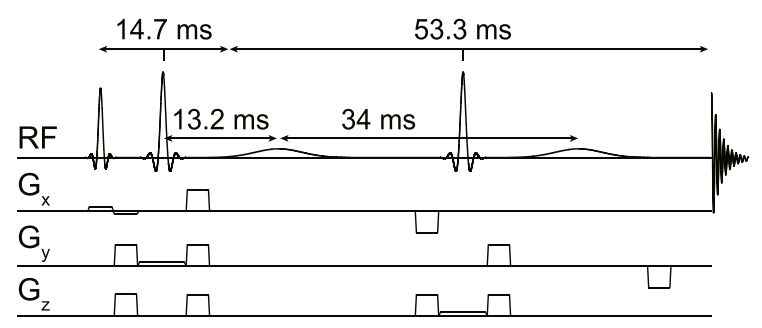

Philips

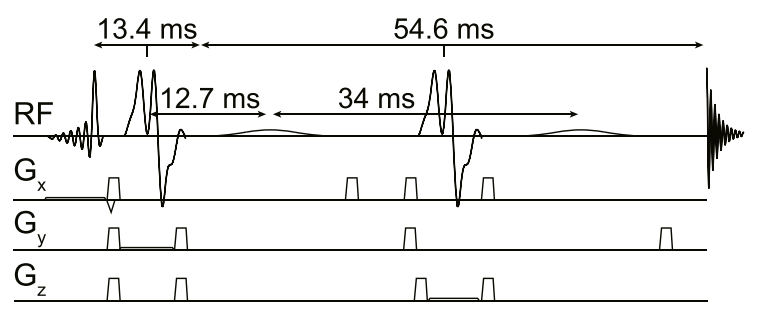

\section{Siemens}
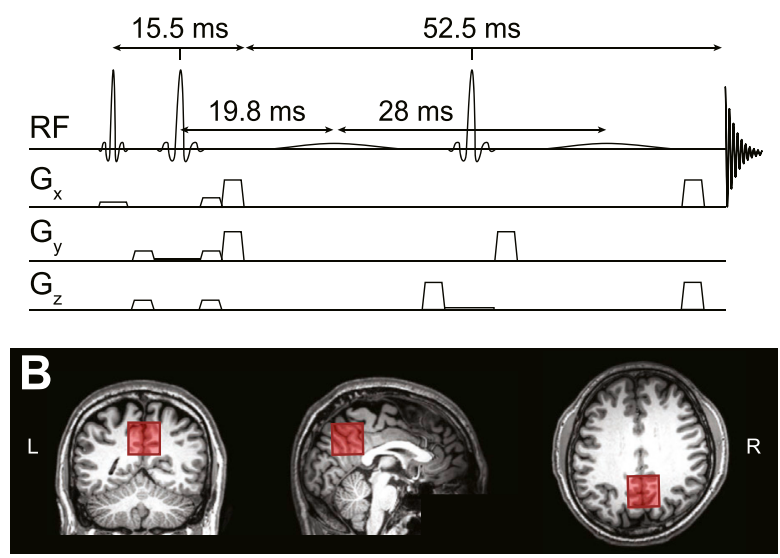

Fig. 1. (A) Pulse sequence diagrams of vendor-specific implementations of MEGA-PRESS at TE $=68 \mathrm{~ms}$. Pulse timings, including TE1/TE2, are indicated. The GE implementation employed a crusher gradient scheme based on the BASING sequence (Star-Lack et al., 1997). The Philips implementation employed non-sinc-based amplitude-modulated refocusing pulses. In the Siemens implementation, the timing between the first and second editing pulse deviates from the optimal TE/2. This slight deviation leads to the GABA signal in the ON scan being nearly, but not fully, refocused. (B) Example MRS voxel placement in the medial parietal lobe of one participant. At each research site, the voxel was rotated in the sagittal plane to be parallel with a line connecting the genu and splenium of the corpus callosum.

the baseline around the $3.0 \mathrm{ppm}$ GABA signal, such that the modeling algorithm converges on a clearly incorrect solution. In such cases, the data were removed from further analysis. Quantitative data quality metrics were also measured, including $N$-acetylaspartate (NAA) and GABA signal-to-noise ratios (SNR), linewidth and average center frequency offset $\overline{\Delta \delta_{0}}$. SNR estimates were measured as the amplitude of the given modeled signal (either NAA in the averaged OFF spectrum, fit with a Lorentzian function, or GABA in the DIFF spectrum) divided by twice the SD of the noise signal. Estimating noise using a consistent methodology across the whole dataset proved surprisingly challenging. Examination of the downfield portion ( $>8 \mathrm{ppm}$ ) of the frequency-domain data revealed signal artifacts in some datasets, likely a result of suboptimal water suppression. Therefore, the following algorithm was employed to estimate artifact-free noise. First, two independent segments of the OFF or DIFF spectrum, 10-11 ppm and 11-12 ppm, were detrended using a second-order polynomial function and the SD of each detrended segment was then calculated. Detrending is required to remove baseline artifacts (often related to the water signal). The smaller of the two SDs was assumed to be the better estimate of noise in each spectrum. The NAA and GABA signal amplitudes were then divided by twice the respective $\mathrm{SD}$ of noise. This approach ensured that variations in baseline and signalrelated artifacts did not bias SNR measurements. Linewidth was measured as the FWHM of the modeled NAA signal. $\overline{\Delta \delta_{0}}$ was calculated as the mean (over the course of the acquisition) difference between the observed frequency of the residual water signal in the pre-frequencycorrected subspectra and the nominal water frequency $\delta_{0}$ at $4.68 \mathrm{ppm}$. It should be noted that using the mean of offset differences does not fully characterize center frequency offsets but is a useful heuristic.

\subsection{Quantification}

The DIFF spectrum was modeled between 2.79 and $4.10 \mathrm{ppm}$ with a three-Gaussian function with a nonlinear baseline to quantify the 3.0 ppm GABA signal and 3.75 ppm glutamate + glutamine (Glx) signals using nonlinear least-squares fitting. The OFF spectrum was modeled between 2.6 and $3.6 \mathrm{ppm}$ with a two-Lorentzian model to quantify creatine $(\mathrm{Cr})$ as an internal reference signal. GABA measurements derived from the GABA+ and MM-suppressed GABA acquisitions were quantified as signal integral ratios: $I_{\mathrm{GABA}} / I_{\mathrm{Cr}}$, where $I_{\mathrm{GABA}}$ is the integral of the modeled $3.0 \mathrm{ppm}$ GABA signal and $I_{\mathrm{Cr}}$ is the integral of the modeled $3.0 \mathrm{ppm} \mathrm{Cr}$ signal. No signal scaling factors were applied. Measurements are denoted GABA+/Cr and MM-suppressed GABA/Cr. Fit quality for each model ( $\left.\varepsilon_{\mathrm{GABA}}, \varepsilon_{\mathrm{Cr}}\right)$ was assessed by normalizing the SD of the model residuals to the amplitude of the respective modeled signal. For GABA, the residuals were limited to the frequency range between 2.79 and $3.55 \mathrm{ppm}$. Overall fit error was then defined as $\sqrt{\varepsilon_{\mathrm{GABA}}^{2}+\varepsilon_{\mathrm{Cr}}^{2}}$.

\subsection{Statistical analysis}

The data had a nested structure. That is, each participant was scanned at one site and each site had a scanner manufactured by one of the three vendors. Therefore, a multilevel model (Hayes, 2006; Peugh, 2010; Snijders and Bosker, 2012) was used for the primary statistical analysis. This approach involves the use of a linear mixed-effects model, an extension of the well-known general linear model, but one which explicitly takes into account systematic effects ascribed to the hierarchical structure of data.

The principal aim of this study was to examine vendor-, site- and participant-related effects on measurement outcomes of GABA-edited MRS. This was achieved by fitting a three-level unconditional linear mixed-effects model to the GABA+ and MM-suppressed GABA data:

$$
\begin{aligned}
y_{i j k} & =\beta_{0}+v_{0 k}+s_{0 j k}+p_{i j k} \\
v_{0 k} & \sim N\left(0, \sigma_{v 0}^{2}\right) \\
s_{0 j k} & \sim N\left(0, \sigma_{s 0}^{2}\right) \\
p_{i j k} & \sim N\left(0, \sigma_{p}^{2}\right)
\end{aligned}
$$

where $y_{i j k}$ is the observed GABA measurement for participant $i$ at site $j$ on a scanner manufactured by vendor $k, \beta_{0}$ is the model intercept (the grand mean), $v_{0 k}$ is the level-3 random effect of vendor, $s_{0 j k}$ is the level-2 random effect of site and $p_{i j k}$ is the level-1 random effect of participant (the residual error). The random effects are assumed to follow a normal distribution with zero mean and constant variance. Since the total variance in the model is equal to the sum of the variance attributed to the three effects, it follows that vendor-, site- and participant-level variance partition coefficients (VPCs) can be respectively calculated as:

$$
\begin{aligned}
& \tau_{v}=\sigma_{v 0}^{2} /\left(\sigma_{v 0}^{2}+\sigma_{s 0}^{2}+\sigma_{p}^{2}\right) \\
& \tau_{s}=\sigma_{s 0}^{2} /\left(\sigma_{v 0}^{2}+\sigma_{s 0}^{2}+\sigma_{p}^{2}\right)
\end{aligned}
$$


$\tau_{p}=\sigma_{p}^{2} /\left(\sigma_{v 0}^{2}+\sigma_{s 0}^{2}+\sigma_{p}^{2}\right)$

Each VPC represents the proportion of total variance in the data accounted for by the specific random effect in the model (Goldstein et al., 2002), in this case, vendor, site and participant.

Secondary multilevel analyses were also performed where fixed effects (predictors) were tested to account for variance attributed to acquisition- and participant-related effects. In this study, the effects of linewidth, NAA SNR, $\overline{\Delta \delta_{0}}$, age and sex on GABA measurement outcome were tested. Such a conditional model with a single predictor is formulated as:

$$
\begin{aligned}
& y_{i j k}=\beta_{0}+v_{0 k}+s_{0 j k}+\left(\beta_{1}+v_{1 k}+s_{1 j k}\right) x_{1 j i k}+p_{i j k} \\
& {\left[\begin{array}{l}
v_{0 k} \\
v_{1 k}
\end{array}\right] \sim N\left\{\left[\begin{array}{l}
0 \\
0
\end{array}\right],\left[\begin{array}{cc}
\sigma_{v 0}^{2} & \sigma_{v 01} \\
\sigma_{v 01} & \sigma_{v 1}^{2}
\end{array}\right]\right\}} \\
& {\left[\begin{array}{l}
s_{0 j k} \\
s_{1 j k}
\end{array}\right] \sim N\left\{\left[\begin{array}{l}
0 \\
0
\end{array}\right],\left[\begin{array}{cc}
\sigma_{s 0}^{2} & \sigma_{s 01} \\
\sigma_{s 01} & \sigma_{s 1}^{2}
\end{array}\right]\right\}} \\
& p_{i j k} \sim N\left(0, \sigma_{p}^{2}\right)
\end{aligned}
$$

This model includes an explanatory variable $\left(x_{1 i j k}\right)$ with a grand mean slope $\left(\beta_{1}\right)$ and by-vendor and by-site random intercepts $\left(v_{0 k}, s_{0 j k}\right)$ and random slopes $\left(v_{1 k}, s_{1 j k}\right)$. At the vendor level, the random effects $v_{0 k}$ and $v_{1 k}$ are assumed to follow a bivariate normal distribution with zero means, variances $\sigma_{v 0}^{2}$ and $\sigma_{v 1}^{2}$ and covariance $\sigma_{v 01}$. The covariance denotes the correlation between the predictor slopes and intercepts. The same definitions apply to the site-level parameters $s_{0 j k}, s_{1 j k}, \sigma_{s 0}^{2}, \sigma_{s 1}^{2}$ and $\sigma_{s 01}$. In this model, both the by-vendor and by-site intercepts and slopes of the explanatory variable are allowed to vary across each level. This "maximal" approach has been shown to reduce Type I error rates in linear mixed-effects models (Barr et al., 2013).

Linear mixed-effects models were fit in $\mathrm{R}$ (version 3.3.3; R Core Team, 2017) using the lme4 package (Bates et al., 2015) and maximum likelihood for model estimation. The outcome and continuous explanatory variables were standardized into $z$-scores to aid model convergence and interpretability of model parameter estimates (Schielzeth, 2010). Goodness-of-fit was calculated as a $\log$-likelihood statistic $(-2 \log L)$. To test for significant random or fixed effects, chi-square likelihood ratio tests were performed by comparing the log-likelihood statistic of one model to that of a reduced model (i.e., a model excluding the random or fixed effect of interest). Likelihood ratio tests were bootstrapped 2,000 times using a parametric bootstrap method (Halekoh and Højsgaard, 2014). If an effect was significant, it was retained in the next assessed model; if not, it was removed. Specifically, the effects of vendor and site were tested first, the effects of acquisition-related variables (linewidth, NAA SNR, $\overline{\Delta \delta_{0}}$ ) were tested second and the effects of participant-related variables (age, sex) were tested last.

A Pearson correlation coefficient was calculated to test the relationship between participants' GABA+/Cr and MM-suppressed GABA/Cr values. This was done by using the residuals of the respective linear mixed-effects model that included only the effects that accounted for a significant amount of variance in either dataset. To illustrate the importance of accounting for systematic effects in the data, a correlational test was also conducted on the raw GABA+/Cr and MM-suppressed $\mathrm{GABA} / \mathrm{Cr}$ values. The correlations were bootstrapped 10,000 times to produce $95 \%$ confidence intervals (CIs) using the bias-corrected and accelerated nonparametric bootstrap method (DiCiccio and Efron, 1996). For all inferential statistical tests, a $p$-value less than 0.05 was considered significant. Corrections for multiple comparisons were not applied.

\section{Results}

GABA-edited MRS data were successfully acquired at all 24 sites. Following quality control analysis, seven GABA+ and 19 MM-suppressed GABA datasets $(3 \%$ and $7 \%$ of the total collected data for either acquisition, respectively) were removed from further analysis. All MMsuppressed GABA data from site G3 were excluded as consistent, excessive center frequency offsets (approximately $-0.1 \mathrm{ppm}$ on average) resulted in extremely small or absent GABA signals. Fig. 2 shows the mean \pm 1 SD GABA+ and MM-suppressed GABA DIFF spectra for each vendor. Examples of the GABA + Glx signal fitting on individual acquisitions are provided in Fig. S1. Distinctive edited GABA peak lineshapes were seen for each vendor, likely a consequence of the different implementations of the MEGA-PRESS sequence between each vendor (Near et al., 2013b). GABA+/Cr and MM-suppressed GABA/Cr values, broken down by site and by vendor, are shown in Fig. 3. Mean \pm 1 SD GABA $+/ \mathrm{Cr}$ values were $0.123 \pm 0.014$ for GE, $0.111 \pm 0.013$ for Philips and $0.116 \pm 0.012$ for Siemens. Across all sites and vendors, GABA $+/ \mathrm{Cr}$ was $0.116 \pm 0.014$. Coefficients of variation (CVs) were $11.5 \%, 11.6 \%$, and $10.7 \%$ for GE, Philips and Siemens, and $12.0 \%$ across all vendors. The mean within-site $\mathrm{CV}$ was $9.5 \%$. Mean MM-suppressed GABA/Cr values (and CVs) were $0.043 \pm 0.013(29.6 \%)$ for GE, $0.044 \pm 0.014$ (30.7\%) for Philips and $0.041 \pm 0.007(17.3 \%)$ for Siemens, and $0.043 \pm 0.012$ (27.6\%) across all sites and vendors. The mean within-site CV was $18.8 \%$. The average ratio between MM-suppressed GABA/Cr and GABA+/Cr was $0.38 \pm 0.11$. Site-level GABA $+/ \mathrm{Cr}$ and MM-suppressed GABA/Cr values are listed in Table 3 .

Fig. 4 shows the distribution of data quality metrics, by site and by vendor, with numerical values included in Table 3 . Mean vendor fit error ranged from $5-6 \%$ for GABA+ editing and 7-9\% for MM-suppressed GABA editing (Fig. 4A). NAA linewidth was within acceptable ranges for 3 T MRS, and approximately equal between the two edited acquisitions (overall: $8.10 \mathrm{~Hz}$ [GABA+] vs. $8.07 \mathrm{~Hz}$ [MM-suppressed GABA]) (Fig. 4B). The Philips data, however, showed lower linewidths on average over both acquisitions $(7.73 \mathrm{~Hz})$ compared to the GE $(8.56 \mathrm{~Hz}$; pairwise comparison: $p<0.001)$ and Siemens $(8.09 \mathrm{~Hz}$; pairwise comparison: $p<0.01$ ) data. NAA SNR estimates were also consistent across acquisition type (overall: $447[\mathrm{GABA}+]$ vs. 439 [MM-suppressed GABA]), though some sites' data exhibited relatively higher SNR values (Fig. 4C). This was most likely driven by differences in RF coil hardware. GABA SNR estimates were mostly consistent within acquisition type (Fig. 4D), with site-to-site variability tending to match the siteto-site variability in NAA SNR estimates. Average frequency offset $\overline{\Delta \delta_{0}}$ varied to a degree across sites, with all Philips sites except P8 having relatively low offset due to the employment of frequency correction during data acquisition (Fig. 4E). As can be seen in Fig. 5A and S2A, the pattern of center frequency offset during acquisition was dominated by random effects and linear drift. In the case of Philips sites, there were additional regular corrections due to real-time center frequency updates. Occasional step-changes or spikes were observed due to participant motion, but these were relatively minor features. The median withinparticipant standard deviation of estimated phase offsets (averaged across acquisition type) was $2.74^{\circ}$ (GE), $1.09^{\circ}$ (Philips) and $5.93^{\circ}$ (Siemens).

\subsection{Multilevel analyses}

Summaries of the linear mixed-effects models for the GABA+ and MM-suppressed GABA data are given in Tables S1 and S2. The initial unconditional multilevel analysis revealed significant effects of vendor $\left[\chi^{2}(1)=2.95, p_{\text {boot }}=0.02\right]$ and site $\left[\chi^{2}(1)=27.93, p_{\text {boot }}<0.001\right]$ on GABA+/Cr measurements. For the MM-suppressed GABA data, site effects were significant $\left[\chi^{2}(1)=111.49, p_{\text {boot }}=0.001\right]$ but vendor effects were not $\left[\chi^{2}(1)<0.1, p_{\text {boot }}=0.60\right]$. The nonsignificant effect of vendor can be better understood by noticing that there was a strong overlap of the vendor-level distributions of MM-suppressed GABA/Cr as shown in Fig. 3B. Consequently, the vendor-level random effect was removed from subsequent models of the MM-suppressed data to simplify model fitting. The VPCs for the unconditional model of the GABA+ data showed that out of the total variance, $8.2 \%$ was attributed to vendor-level differences, 
A

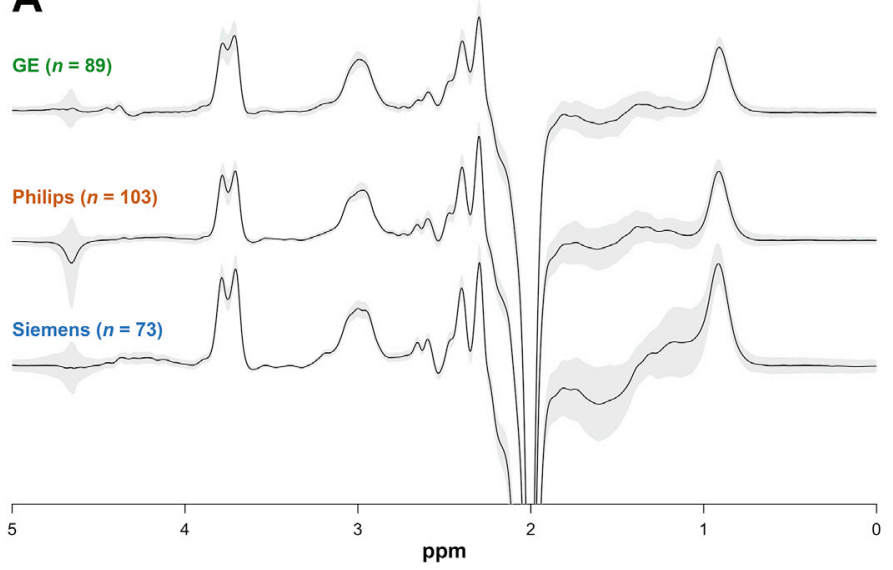

B

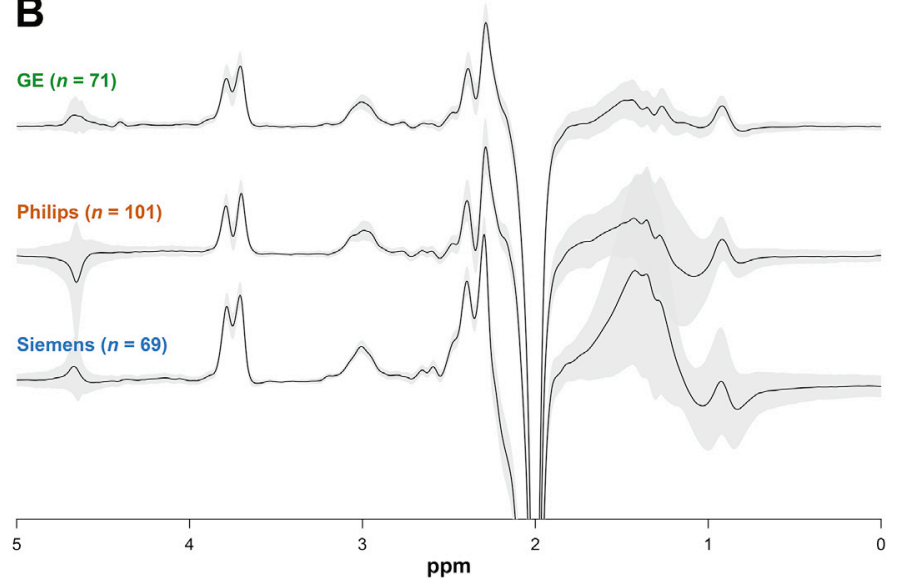

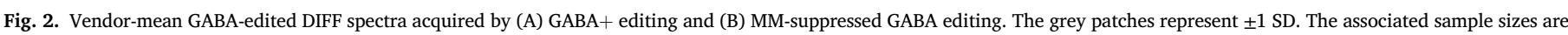

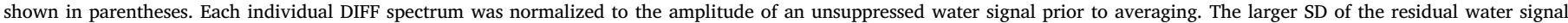

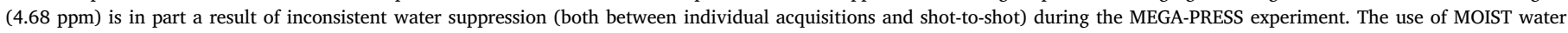
suppression by some Philips sites also contributed to the larger SD in the mean Philips spectra.

$19.7 \%$ was attributed to site-level differences and $72.1 \%$ was attributed to participant-level differences. In the MM-suppressed GABA data, 50.4\% of the total variance was attributed to site-level differences and $49.6 \%$ was attributed to participant-level differences.

Results of the secondary multilevel analyses showed no significant effects of linewidth or NAA SNR on GABA $+/ \mathrm{Cr}\left[\chi^{2}(5)=3.30\right.$, $p_{\text {boot }}=0.31$ and $\chi^{2}(5)=0.25, p_{\text {boot }}=0.95$, respectively $]$ or on MMsuppressed GABA $/ \mathrm{Cr}\left[\chi^{2}(3)=0.08, p_{\text {boot }}=0.98\right.$ and $\chi^{2}(3)=5.32$, $p_{\text {boot }}=0.10$, respectively] measurements. Average frequency offset $\overline{\Delta \delta_{0}}$ was, however, significantly associated with both $\mathrm{GABA}+/ \mathrm{Cr}$ $\left[\chi^{2}(5)=11.72, \quad p_{\text {boot }}=0.005\right]$ and MM-suppressed GABA/Cr $\left[\chi^{2}(3)=44.31, p_{\text {boot }}<0.001\right]$ measurements. Of the variance remaining after accounting for site and vendor effects, $\overline{\Delta \delta_{0}}$ accounted for $4.0 \%$ of variance in the GABA+ data and $21.0 \%$ of variance in the MMsuppressed GABA data. The association between $\overline{\Delta \delta_{0}}$ and MMsuppressed GABA/Cr is shown in Fig. 5. By-site regression lines are consistent across sites and vendor, indicating a robust relationship. The same plot for GABA+/Cr is shown in Fig. S2.

Finally, the effects of age and sex on GABA measurement outcome were examined, after adjusting for $\overline{\Delta \delta_{0}}$, but no significant effects on either GABA+/Cr [age: $\chi^{2}(7)=3.52, p_{\text {boot }}=0.31$; sex: $\chi^{2}(7)=0.37$, $p_{\text {boot }}=0.95$ ] or MM-suppressed GABA/Cr [age: $\chi^{2}(4)=3.21$, $p_{\text {boot }}=0.33$; sex: $\left.\chi^{2}(4)=3.87, p_{\text {boot }}=0.24\right]$ were observed.

\subsection{Correlational analysis}

A correlational analysis of the residuals of the linear mixed-models including $\overline{\Delta \delta_{0}}$ as a predictor showed that $\mathrm{GABA}+/ \mathrm{Cr}$ and $\mathrm{MM}$ suppressed GABA/Cr were significantly correlated ( $r=0.25,95 \% \mathrm{CI}$ : $[0.15,0.35], p<0.001$ ) (Fig. 6). Specifically, the shared variance between the two measurements, after adjusting for site, vendor and frequency offset effects, amounted to $6.3 \%$.

\section{Discussion}

This is the largest multi-site study to date applying GABA-edited MRS in the human brain. The aims at the outset were to establish the extent to which GABA-edited measurements are influenced by site-, sequence- and vendor-specific differences, and to investigate sources of observed variance. Overall, the major findings can be summarized as follows:

1) The agreement between GABA+ values was surprisingly good, with whole-dataset CV (12\%) not much higher than the mean within-site
CV (10\%), although site and vendor both contributed significantly to total variance.

2) Agreement between MM-suppressed GABA values was less good than GABA + values, with much higher whole-dataset (28\%) and mean within-site (19\%) CVs. The amount of absolute variance in the MMsuppressed GABA data was, however, similar to the GABA+ data.

3) Average center frequency offset was a significant factor in both experiments, explaining a greater percentage of variance in the MMsuppressed experiment (21\%) than in the GABA+ experiment (4\%) after accounting for variance attributed to site and vendor effects.

The level of agreement between GABA + measurement outcomes was better than anticipated. The whole-dataset CV reported in this study falls well within the range of inter-individual CVs observed for edited GABA+ measurements in the literature: 6-24\% (Bogner et al., 2010; Evans et al., 2010; Geramita et al., 2011; Long et al., 2015; Mikkelsen et al., 2016a; O'Gorman et al., 2011). That a majority of the total variance in the data was participant-level variance indicates that initial steps taken to standardize acquisition parameters across vendors (most notably TR, TE and editing pulse bandwidth) were largely successful. The dominant proportion of variance attributed to within-site (i.e., betweenparticipant) variability may in large part reflect a greater level of experience with the GABA+-edited acquisition across all platforms and greater success in standardizing the acquisitions (as well as a greater inherent robustness of this sequence to minor differences such as $B_{0}$ field offsets).

The protocols used in this study may be considered as a standard, with the currently published data serving as a benchmark for sites applying GABA-edited MRS. Although the majority of sites within-vendor used the same pulse sequence, there were differences. One GE site (G1) used a different MEGA-PRESS implementation to the others, and had the lowest average $\mathrm{GABA}+/ \mathrm{Cr}$ and highest average MM-suppressed GABA/Cr values within-vendor. One Philips site (P8) did not use prospective frequency correction, and gave the lowest average GABA+/Cr values and highest average MM-suppressed GABA/Cr values within-vendor. Two Siemens sites had locally modified sequences (compared to the rest), and one of these (S7) had the highest average GABA+/Cr values withinvendor. Thus, even small differences in sequence implementation seem to be enough to differentiate sites from the group. Further efforts to standardize sequence timings and editing pulse shapes within and between vendors would be expected to reduce vendor- and site-level variance. At this stage, both GE and Siemens have vendor-distributed sequences in place, using proprietary RF pulse shapes, so this further standardization is a challenge to be taken up by the edited 

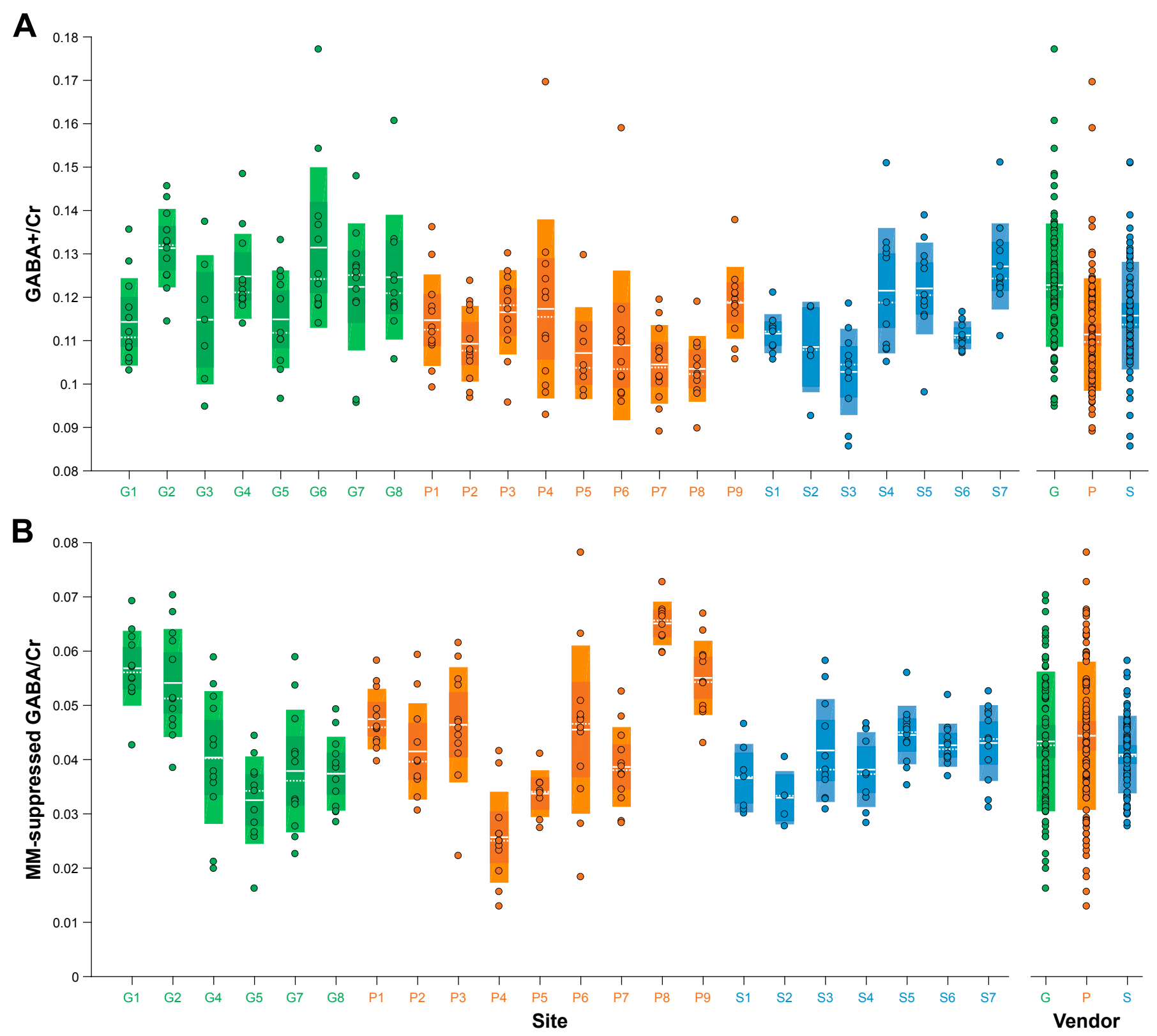

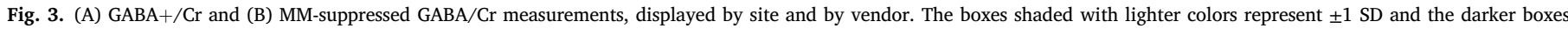

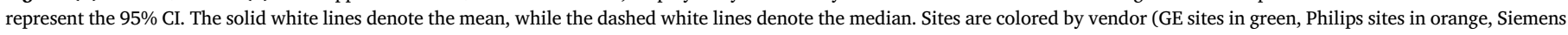
sites in blue).

\section{MRS community.}

At this stage, it is clear that the MM suppression methodology is less consistent than the GABA+ method, with higher rates of data rejection (19 MM-suppressed GABA datasets vs. seven GABA+ datasets) and greater relative variance. One major contributor of variance that has been identified is frequency offset, with the data reproducing the approximately linear relationship observed by Edden et al. (2016). The ratio between MM-suppressed GABA and GABA+ measurements ( 0.38 ) is lower than expected. Typically, it is assumed that $\sim 50 \%$ of the GABA+ signal is GABA (Harris et al., 2015a; Mikkelsen et al., 2016a; Shungu et al., 2016). This is largely explained by differential $T_{2}$ relaxation between GABA signal at $\mathrm{TE}=68 \mathrm{~ms}$ and $\mathrm{TE}=80 \mathrm{~ms}(13 \%$ edited signal loss based on a $T_{2}$ of $88 \mathrm{~ms}$ (Edden et al., 2012b)) and artificially reduced "MM-suppressed GABA" values due to negative MM co-editing ( $\sim 5 \%$ edited signal loss due to mean $\overline{\Delta \delta_{0}}$ of $-0.005 \mathrm{ppm}$ (see Edden et al., 2016)). The fraction of GABA+ signal that is MM will depend on the bandwidth of the editing pulse used, as will GABA signal losses in the
MM-suppressed experiment. While differences in TE between vendors in the MM-suppressed acquisition added a level of methodological heterogeneity, the multilevel analysis did not consider vendor-level effects in the MM-suppressed data to be of statistical importance, in line with previous findings of a minimal effect of TE on the edited GABA signal between 68 and 80 ms (Edden et al., 2012c; Mikkelsen et al., 2016a). These data provide further evidence to support the recommendation of prospective frequency correction for MM-suppressed GABA-edited acquisitions (Edden et al., 2016). For most applications, it is more important that MM suppression removes MM-related variance, rather than MM signal per se. The greater variance in the MM-suppressed GABA data may also explain the weak correlation between GABA+/Cr and MMsuppressed GABA/Cr to some degree (although the statistical modeling approach used, which removes, e.g., site-level variance in the measures, is relatively conservative and will remove some real biologically driven variance).

One important strength of this dataset, in support of edited MRS of 
Table 3

Quantification and data quality metrics for the GABA + and MM-suppressed GABA data, displayed by site and by vendor (shown as mean \pm SD).

\begin{tabular}{|c|c|c|c|c|c|c|c|c|c|c|c|c|}
\hline \multirow[t]{2}{*}{ Site ID } & \multicolumn{2}{|l|}{$\mathrm{GABA} / \mathrm{Cr}$} & \multicolumn{2}{|l|}{ Fit error (\%) } & \multicolumn{2}{|c|}{ Linewidth (Hz) } & \multicolumn{2}{|l|}{ NAA SNR } & \multicolumn{2}{|c|}{ GABA SNR } & \multicolumn{2}{|l|}{$\overline{\Delta \delta_{0}}(\mathrm{ppm})$} \\
\hline & GABA + & MM-s GABA & GABA + & MM-s GABA & GABA + & MM-s GABA & GABA + & MM-s GABA & GABA + & MM-s GABA & GABA + & MM-s GABA \\
\hline G1 & $0.11 \pm 0.01$ & $0.06 \pm 0.01$ & $4.59 \pm 0.63$ & $6.16 \pm 1.21$ & $8.68 \pm 0.66$ & $8.70 \pm 0.70$ & $350 \pm 58$ & $343 \pm 49$ & $21 \pm 3$ & $10 \pm 2$ & $0.015 \pm 0.012$ & $0.014 \pm 0.011$ \\
\hline G2 & $0.13 \pm 0.01$ & $0.05 \pm 0.01$ & $6.16 \pm 1.99$ & $8.02 \pm 3.05$ & $8.38 \pm 0.63$ & $8.55 \pm 0.81$ & $418 \pm 76$ & $412 \pm 63$ & $27 \pm 5$ & $12 \pm 3$ & $-0.010 \pm 0.012$ & $-0.014 \pm 0.013$ \\
\hline G3 & $0.11 \pm 0.01$ & $\mathrm{DE}$ & $6.87 \pm 1.39$ & $\mathrm{DE}$ & $9.07 \pm 1.54$ & $\mathrm{DE}$ & $380 \pm 29$ & $\mathrm{DE}$ & $23 \pm 3$ & $\mathrm{DE}$ & $-0.054 \pm 0.027$ & $\mathrm{DE}$ \\
\hline G4 & $0.12 \pm 0.01$ & $0.04 \pm 0.01$ & $5.32 \pm 1.36$ & $10.32 \pm 3.49$ & $8.93 \pm 0.74$ & $9.07 \pm 1.10$ & $285 \pm 41$ & $279 \pm 49$ & $18 \pm 3$ & $7 \pm 2$ & $-0.017 \pm 0.011$ & $-0.016 \pm 0.015$ \\
\hline G5 & $0.11 \pm 0.01$ & $0.03 \pm 0.01$ & $6.26 \pm 2.40$ & $10.11 \pm 3.20$ & $8.62 \pm 0.65$ & $8.43 \pm 0.72$ & $503 \pm 90$ & $445 \pm 73$ & $26 \pm 3$ & $8 \pm 2$ & $0.003 \pm 0.021$ & $0.004 \pm 0.021$ \\
\hline G6 & $0.13 \pm 0.02$ & DNA & $6.58 \pm 1.24$ & DNA & $7.94 \pm 0.47$ & DNA & $427 \pm 88$ & DNA & $23 \pm 4$ & DNA & $-0.005 \pm 0.009$ & DNA \\
\hline G7 & $0.12 \pm 0.01$ & $0.04 \pm 0.01$ & $7.06 \pm 1.84$ & $10.78 \pm 2.78$ & $8.64 \pm 0.67$ & $8.67 \pm 0.65$ & $390 \pm 70$ & $345 \pm 72$ & $23 \pm 5$ & $9 \pm 2$ & $-0.023 \pm 0.014$ & $-0.026 \pm 0.015$ \\
\hline G8 & $0.12 \pm 0.01$ & $0.04 \pm 0.01$ & $7.40 \pm 2.71$ & $11.25 \pm 3.24$ & $8.17 \pm 0.60$ & $8.10 \pm 0.51$ & $322 \pm 67$ & $330 \pm 58$ & $19 \pm 3$ & $8 \pm 2$ & $-0.02 \pm 0.012$ & $-0.020 \pm 0.01$ \\
\hline All GE & $0.12 \pm 0.01$ & $0.04 \pm 0.01$ & $6.24 \pm 1.95$ & $9.43 \pm 3.34$ & $8.53 \pm 0.79$ & $8.59 \pm 0.80$ & $384 \pm 93$ & $358 \pm 80$ & $23 \pm 5$ & $9 \pm 3$ & $-0.012 \pm 0.022$ & $-0.010 \pm 0.02$ \\
\hline P1 & $0.11 \pm 0.01$ & $0.05 \pm 0.01$ & $4.91 \pm 0.49$ & $6.42 \pm 1.13$ & $7.53 \pm 0.39$ & $7.41 \pm 0.35$ & $457 \pm 76$ & $495 \pm 83$ & $25 \pm 5$ & $11 \pm 2$ & $-0.006 \pm 0.005$ & $-0.004 \pm 0.005$ \\
\hline P2 & $0.11 \pm 0.01$ & $0.04 \pm 0.01$ & $4.83 \pm 0.73$ & $8.48 \pm 1.99$ & $7.43 \pm 0.39$ & $7.55 \pm 0.35$ & $448 \pm 73$ & $421 \pm 75$ & $22 \pm 4$ & $9 \pm 2$ & $0.002 \pm 0.003$ & $0.0001 \pm 0.003$ \\
\hline P3 & $0.12 \pm 0.01$ & $0.05 \pm 0.01$ & $5.40 \pm 0.76$ & $8.70 \pm 1.69$ & $7.88 \pm 0.49$ & $7.96 \pm 0.46$ & $351 \pm 47$ & $342 \pm 64$ & $19 \pm 3$ & $8 \pm 2$ & $-0.009 \pm 0.007$ & $-0.009 \pm 0.009$ \\
\hline P4 & $0.12 \pm 0.02$ & $0.03 \pm 0.01$ & $6.40 \pm 1.69$ & $18.10 \pm 9.76$ & $7.41 \pm 0.33$ & $7.44 \pm 0.37$ & $466 \pm 56$ & $481 \pm 88$ & $26 \pm 5$ & $6 \pm 1$ & $0.004 \pm 0.003$ & $0.005 \pm 0.004$ \\
\hline P5 & $0.11 \pm 0.01$ & $0.03 \pm 0.00$ & $4.60 \pm 0.76$ & $8.86 \pm 2.04$ & $7.74 \pm 0.39$ & $7.69 \pm 0.38$ & $473 \pm 107$ & $484 \pm 76$ & $26 \pm 3$ & $9 \pm 1$ & $-0.009 \pm 0.004$ & $-0.004 \pm 0.004$ \\
\hline P6 & $0.11 \pm 0.02$ & $0.05 \pm 0.02$ & $6.17 \pm 0.89$ & $11.95 \pm 4.59$ & $7.73 \pm 0.47$ & $7.65 \pm 0.37$ & $340 \pm 48$ & $356 \pm 47$ & $19 \pm 5$ & $8 \pm 2$ & $-0.005 \pm 0.005$ & $-0.001 \pm 0.005$ \\
\hline P7 & $0.10 \pm 0.01$ & $0.04 \pm 0.01$ & $5.37 \pm 0.69$ & $8.06 \pm 2.56$ & $9.08 \pm 0.66$ & $8.92 \pm 0.59$ & $418 \pm 60$ & $448 \pm 80$ & $24 \pm 3$ & $9 \pm 2$ & $0.010 \pm 0.005$ & $0.010 \pm 0.006$ \\
\hline P8 & $0.10 \pm 0.01$ & $0.07 \pm 0.00$ & $4.72 \pm 0.50$ & $4.11 \pm 0.51$ & $7.35 \pm 0.44$ & $7.43 \pm 0.42$ & $659 \pm 101$ & $646 \pm 139$ & $34 \pm 5$ & $22 \pm 3$ & $0.018 \pm 0.028$ & $0.022 \pm 0.027$ \\
\hline P9 & $0.12 \pm 0.01$ & $0.06 \pm 0.01$ & $4.88 \pm 0.70$ & $5.11 \pm 0.98$ & $7.41 \pm 0.23$ & $7.35 \pm 0.26$ & $458 \pm 68$ & $479 \pm 65$ & $26 \pm 3$ & $13 \pm 3$ & $-0.004 \pm 0.004$ & $-0.0004 \pm 0.005$ \\
\hline All Philips & $0.11 \pm 0.01$ & $0.04 \pm 0.01$ & $5.28 \pm 1.04$ & $8.96 \pm 5.56$ & $7.73 \pm 0.67$ & $7.72 \pm 0.62$ & $449 \pm 110$ & $457 \pm 114$ & $25 \pm 6$ & $11 \pm 5$ & $0.0003 \pm 0.013$ & $0.002 \pm 0.013$ \\
\hline S1 & $0.11 \pm 0.00$ & $0.04 \pm 0.01$ & $5.63 \pm 1.00$ & $5.39 \pm 0.77$ & $8.65 \pm 1.33$ & $8.47 \pm 1.56$ & $556 \pm 103$ & $562 \pm 58$ & $27 \pm 4$ & $14 \pm 3$ & $-0.022 \pm 0.011$ & $-0.031 \pm 0.012$ \\
\hline S2 & $0.11 \pm 0.01$ & $0.03 \pm 0.00$ & $4.73 \pm 0.46$ & $7.17 \pm 1.06$ & $8.79 \pm 0.43$ & $8.89 \pm 0.38$ & $480 \pm 99$ & $473 \pm 55$ & $25 \pm 4$ & $10 \pm 1$ & $0.007 \pm 0.017$ & $0.010 \pm 0.011$ \\
\hline S3 & $0.10 \pm 0.01$ & $0.04 \pm 0.01$ & $6.79 \pm 0.82$ & $8.81 \pm 3.05$ & $7.73 \pm 0.44$ & $7.74 \pm 0.46$ & $379 \pm 65$ & $377 \pm 97$ & $16 \pm 4$ & $11 \pm 3$ & $0.007 \pm 0.015$ & $0.004 \pm 0.023$ \\
\hline S4 & $0.12 \pm 0.01$ & $0.04 \pm 0.01$ & $5.63 \pm 0.50$ & $7.47 \pm 1.26$ & $7.63 \pm 0.24$ & $7.49 \pm 0.22$ & $565 \pm 104$ & $489 \pm 80$ & $25 \pm 4$ & $12 \pm 3$ & $-0.015 \pm 0.007$ & $-0.024 \pm 0.009$ \\
\hline S5 & $0.12 \pm 0.01$ & $0.04 \pm 0.01$ & $5.98 \pm 0.76$ & $6.64 \pm 1.35$ & $8.43 \pm 1.14$ & $8.40 \pm 1.27$ & $373 \pm 56$ & $347 \pm 40$ & $18 \pm 1$ & $10 \pm 1$ & $-0.003 \pm 0.013$ & $-0.009 \pm 0.017$ \\
\hline s6 & $0.11 \pm 0.00$ & $0.04 \pm 0.00$ & $5.22 \pm 0.73$ & $5.00 \pm 1.19$ & $7.94 \pm 0.47$ & $8.06 \pm 0.61$ & $585 \pm 90$ & $568 \pm 166$ & $28 \pm 3$ & $15 \pm 2$ & $-0.009 \pm 0.012$ & $-0.011 \pm 0.015$ \\
\hline S7 & $0.13 \pm 0.01$ & $0.04 \pm 0.01$ & $5.08 \pm 0.76$ & $5.92 \pm 1.97$ & $7.97 \pm 0.49$ & $7.97 \pm 0.48$ & $689 \pm 151$ & $653 \pm 108$ & $47 \pm 10$ & $25 \pm 9$ & $-0.004 \pm 0.013$ & $-0.016 \pm 0.021$ \\
\hline All Siemens & $0.12 \pm 0.01$ & $0.04 \pm 0.01$ & $5.64 \pm 0.94$ & $6.61 \pm 2.11$ & $8.10 \pm 0.83$ & $8.07 \pm 0.88$ & $522 \pm 148$ & $495 \pm 146$ & $27 \pm 11$ & $14 \pm 7$ & $-0.006 \pm 0.015$ & $-0.012 \pm 0.020$ \\
\hline Overall & $0.116 \pm 0.014$ & $0.043 \pm 0.012$ & $5.70 \pm 1.45$ & $8.43 \pm 4.33$ & $8.10 \pm 0.83$ & $8.07 \pm 0.83$ & $447 \pm 128$ & $439 \pm 128$ & $25 \pm 8$ & $11 \pm 5$ & $-0.006 \pm 0.018$ & $-0.005 \pm 0.018$ \\
\hline
\end{tabular}

DE, data excluded; DNA, data not acquired; MM-s, MM-suppressed. 

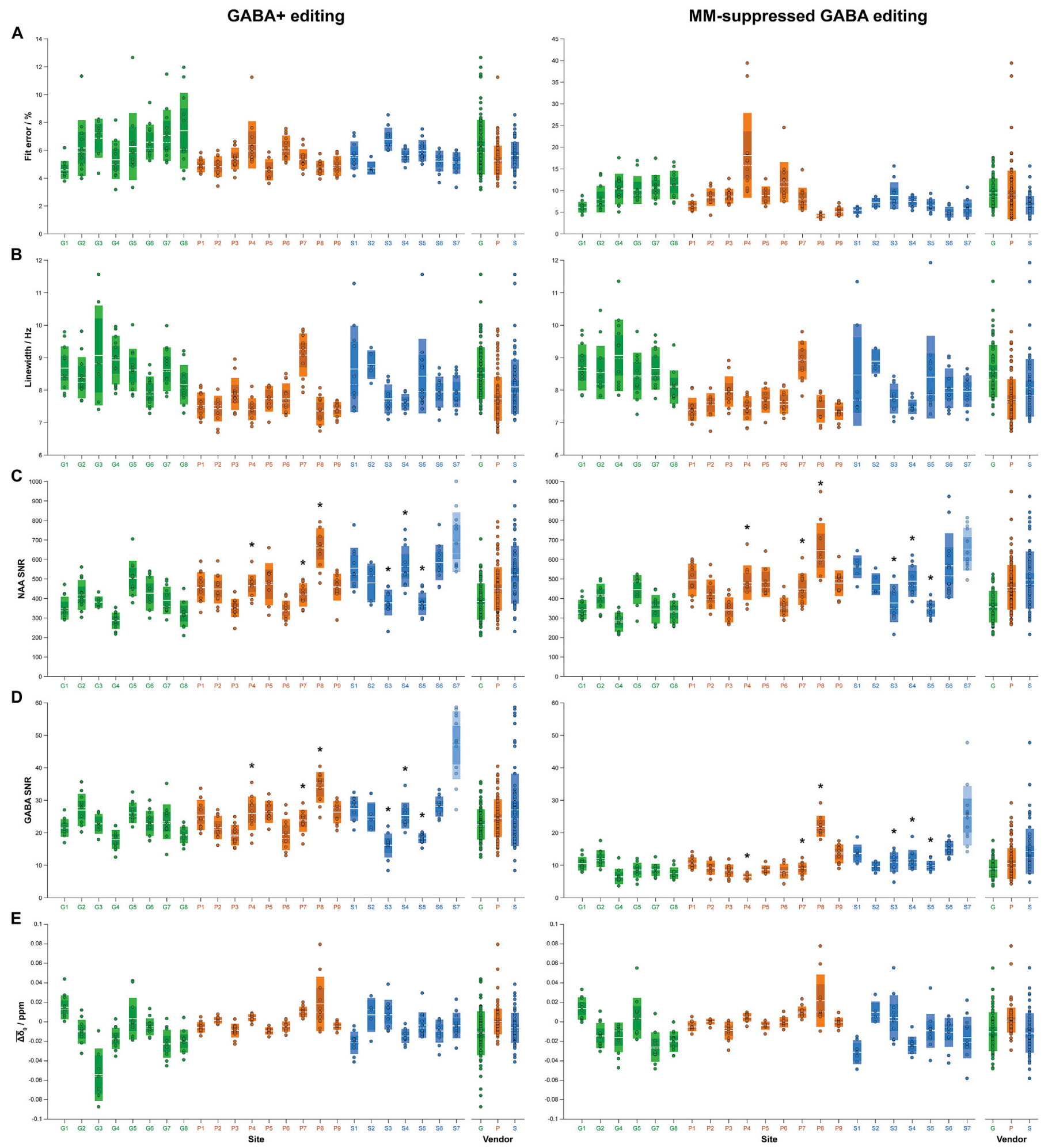

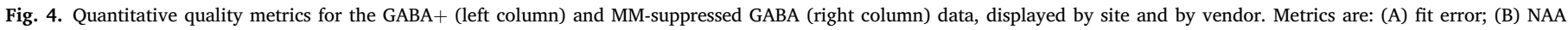

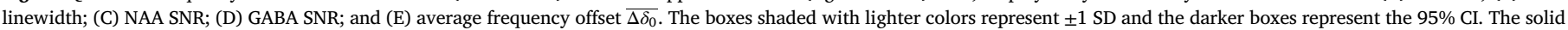

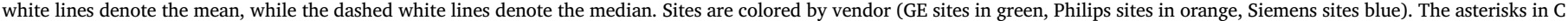

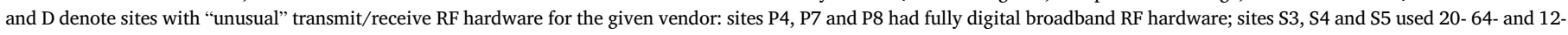

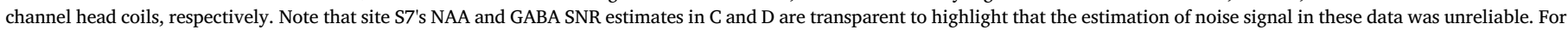

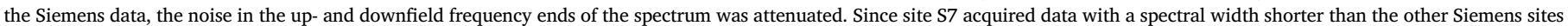
(-3.5-13 ppm), the attenuated noise led to upward-biased SNR values. 


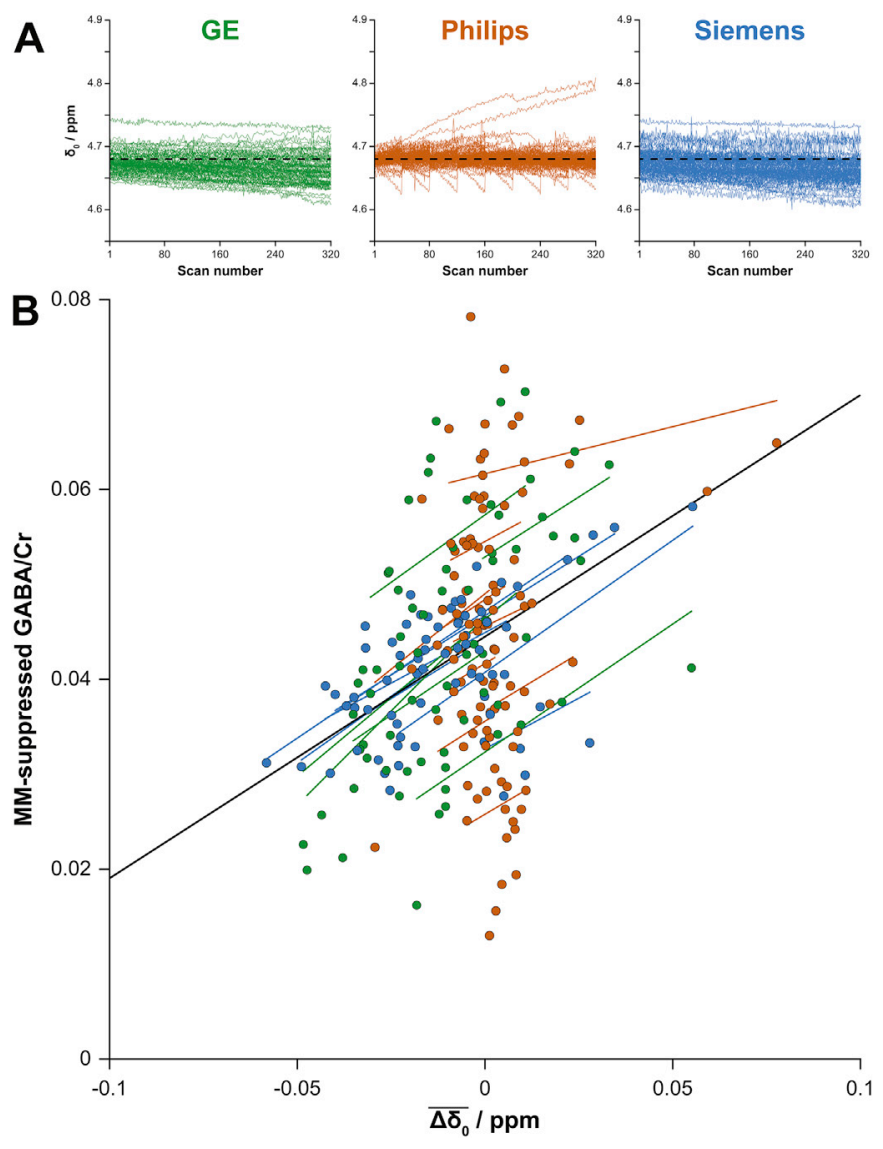

Fig. 5. (A) $B_{0}$ field changes during the MM-suppressed GABA editing experiment. The observed frequency of the residual water signal in each subspectrum is plotted against the scan number over the course of the acquisition (320 averages, $\sim 10 \mathrm{~min}$ ). Data from all participants are overlaid (separated by vendor). The dashed black lines represent the nominal water frequency $(4.68 \mathrm{ppm})$. (B) Scatterplot illustrating the relationship between average frequency offset $\overline{\Delta \delta_{0}}$ and MM-suppressed GABA/Cr as determined by the linear mixed-effects model. Individual measurements are color-coded by vendor (GE in green, Philips in orange, Siemens in blue). The black regression line shows the relationship between $\overline{\Delta \delta_{0}}$ and MM-suppressed GABA/Cr over the entire dataset. Additional color-coded regression lines are shown for each site.
GABA, is the fact that, even over so large a dataset as this, there was no significant relationship between GABA measurements and independent metrics of data quality, such as NAA SNR and linewidth. Thus, even though the data quality metrics did vary site-to-site to some degree, tolerable levels (in the sense of not impacting GABA measurements) were achieved at all sites. However, it is acknowledged that these data were homogeneously acquired from a large voxel in a brain region where relatively favorable linewidth and SNR can be achieved. In contrast, associations between metabolite measurements, or their uncertainty, and SNR and/or linewidth are widely observed in investigations of linearcombination modeling of unedited spectra (Bartha, 2007; Kanowski et al., 2004; Near et al., 2013a). With spectral editing, the goal is to attain an unambiguously resolved signal that allows for simple peak fitting and integration (Bogner et al., 2016; Harris et al., 2017), but with (short-TE) unedited spectra quantification is based on linear-combination fitting, the outcome of which depends on the degree of orthogonality of the basis-set, which itself depends on data quality (Graveron-Demilly, 2014). Although edited MRS of lower-concentration metabolites typically necessitates comparatively longer scan durations or larger voxels to achieve reasonable SNR, the advent of multiplexed editing (Chan et al., 2016, 2017a, 2017b; Oeltzschner et al., 2017; Saleh et al., 2016) and development of edited MRSI (Bogner et al., 2014; Hnilicová et al., 2016; Zhu et al., 2011) continues to improve the efficiency of spectral editing approaches.

A number of multi-site MRS studies have been conducted in the past, each with a specific focus. These focuses have included: unedited, shortTE MRS (Deelchand et al., 2015); low-field MRS (Träber et al., 2006); ultra-high field MRS (van de Bank et al., 2015); absolute quantification (Bovée et al., 1998; De Beer et al., 1998; Keevil et al., 1998; Soher et al., 1996); MRSI (Sabati et al., 2015; Wijnen et al., 2010); body MRS (Bolan et al., 2016; Scheenen et al., 2011); brain tumor classification (GarcíaGómez et al., 2009; Julià-Sapé et al., 2006; Tate et al., 2003; Vicente et al., 2013); and HIV-associated dementia (Chang et al., 2004; Lee et al., 2003; Sacktor et al., 2005). Even for short-TE methods, the degree of agreement between sites and scanners is highly dependent on the degree of acquisition homogeneity.

Edited MRS of GABA has a number of limitations, which are not directly addressed in this paper. The fact that MM-suppressed GABA measurements are so susceptible to $B_{0}$ field changes resulting from scanner drift and participant head motion means that GABA+ is still the most widely used edited GABA measure, in spite of the $\sim 50 \% \mathrm{MM}$ contribution. However, measures of GABA that effectively remove the
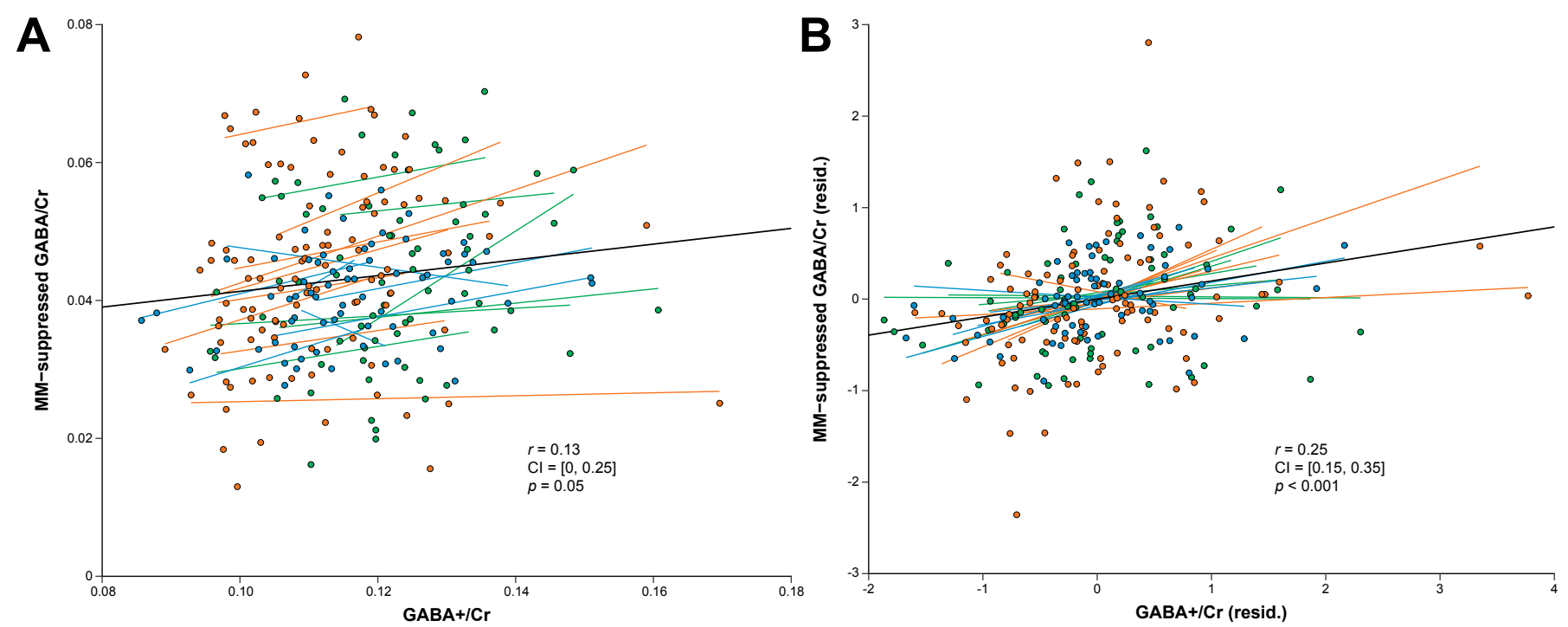

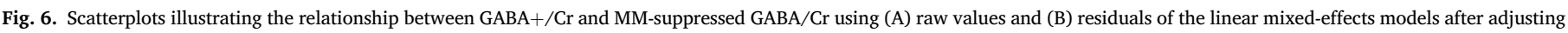
for systematic effects of vendor, site and $\overline{\Delta \delta_{0}}$. The Pearson correlation coefficients and $p$-values are shown, as are the $95 \%$ CIs of the coefficients. 
MM contamination would have clearer biochemical significance than $\mathrm{GABA}+$ measurements, and this paper establishes the importance of future research dedicated to obtaining MM-suppressed GABA measures with less sensitivity to $B_{0}$ field offsets. The application of MM suppression is strongly motivated by the desire to remove MM-related variance, and further development to improve the robustness of MM suppression remains important. Even without this MM contamination, the interpretation of MRS measures of total GABA concentration is complex - and the extent to which it is an index of GABAergic neurotransmission (beyond simply being a marker of GABAergic interneuron cell density) is the subject of ongoing debate (Myers et al., 2016; Rae, 2014; Stagg et al., 2011). This paper also does not explore the complexities of GABA quantification by tissue water-referencing, a popular alternative to $\mathrm{Cr}$ referencing. Additional aspects of water-referenced quantification (such as site-to-site segmentation differences) will contribute to the variability of water-referenced GABA measurements across vendors, research sites and individuals (e.g., see Gasparovic et al., 2006; Harris et al., 2015b; Mikkelsen et al., 2016b).

In conclusion, an international consortium collected a large dataset of GABA-edited MRS measurements, the first study of this size for in vivo MRS of GABA. These data support the use of GABA-edited MRS for multisite, multi-vendor studies, with site and vendor contributing a surprisingly small amount of total variance to GABA+ measurements.

\section{Acknowledgments}

This work was supported by NIH grants R01 EB016089, R01 EB023963 and P41 EB015909. Data collection was supported by the Shandong Provincial Key Research and Development Plan of China (2016ZDJS07A16) and the National Natural Science Foundation of China for Young Scholars (no. 81601479). IDW thanks Mrs. J. Bigley of the University of Sheffield MRI Unit for her assistance with data acquisition. JJP was supported by NIAAA grant K23 AA020842. MPS was supported by NIH grant F32 EY025121. NAJP receives salary support from NIH grant K99 MH107719. The authors acknowledge implementation contributions from a number of employees of Siemens Medical Solutions, including Dr. Keith Heberlein and Dr. Sinyeob Ahn, to the Siemens WIP sequences, which are shared with several research sites under sequencespecific agreements.

\section{Appendix A. Supplementary data}

Supplementary data related to this article can be found at http://dx. doi.org/10.1016/j.neuroimage.2017.07.021.

\section{References}

Barr, D.J., Levy, R., Scheepers, C., Tily, H.J., 2013. Random effects structure for confirmatory hypothesis testing: keep it maximal. J. Mem. Lang. 68, 255-278. http:// dx.doi.org/10.1016/j.jml.2012.11.001.

Bartha, R., 2007. Effect of signal-to-noise ratio and spectral linewidth on metabolite quantification at 4 T. NMR Biomed. 20, 512-521. http://dx.doi.org/10.1002/ nbm.1122.

Bates, D., Mächler, M., Bolker, B.M., Walker, S.C., 2015. Fitting linear mixed-effects models using lme4. J. Stat. Softw. 67 http://dx.doi.org/10.18637/jss.v067.i01.

Bhagwagar, Z., Wylezinska, M., Jezzard, P., Evans, J., Boorman, E., Matthews P, M., Cowen P, J., 2008. Low GABA concentrations in occipital cortex and anterior cingulate cortex in medication-free, recovered depressed patients. Int. J. Neuropsychopharmacol. 11, 255-260. http://dx.doi.org/10.1017/ S1461145707007924.

Bogner, W., Gagoski, B., Hess, A.T., Bhat, H., Tisdall, M.D., van der Kouwe, A.J.W., Strasser, B., Marjańska, M., Trattnig, S., Grant, E., Rosen, B., Andronesi, O.C., 2014 3D GABA imaging with real-time motion correction, shim update and reacquisition of adiabatic spiral MRSI. Neuroimage 103, 290-302. http://dx.doi.org/10.1016/ j.neuroimage.2014.09.032.

Bogner, W., Gruber, S., Doelken, M., Stadlbauer, A., Ganslandt, O., Boettcher, U., Trattnig, S., Doerfler, A., Stefan, H., Hammen, T., 2010. In vivo quantification of intracerebral GABA by single-voxel ${ }^{1} \mathrm{H}-\mathrm{MRS}$ - how reproducible are the results? Eur. J. Radiol. 73, 526-531. http://dx.doi.org/10.1016/j.ejrad.2009.01.014.

Bogner, W., Hangel, G., Esmaeili, M., Andronesi, O.C., 2016. 1D-spectral editing and 2D multispectral in vivo ${ }^{1} \mathrm{H}$-MRS and ${ }^{1} \mathrm{H}$-MRSI - methods and applications. Anal. Biochem. http://dx.doi.org/10.1016/j.ab.2016.12.020.
Bolan, P.J., Kim, E., Herman, B.A., Newstead, G.M., Rosen, M.A., Schnall, M.D., Pisano, E.D., Weatherall, P.T., Morris, E.A., Lehman, C.D., Garwood, M., Nelson, M.T., Yee, D., Polin, S.M., Esserman, L.J., Gatsonis, C.A., Metzger, G.J., Newitt, D.C., Partridge, S.C., Hylton, N.M., 2016. MR spectroscopy of breast cancer for assessing early treatment response: results from the ACRIN 6657 MRS trial. J. Magn. Reson. Imaging. http://dx.doi.org/10.1002/jmri.25560.

Bollmann, S., Ghisleni, C., Poil, S., Martin, E., Ball, J., Eich-Höchli, D., Edden, R.A.E., Klaver, P., Michels, L., Brandeis, D., O'Gorman, R.L., 2015. Developmental changes in gamma-aminobutyric acid levels in attention-deficit/hyperactivity disorder. Transl Psychiatry 5, e589. http://dx.doi.org/10.1038/tp.2015.79.

Bottomley, P.A., 1987. Spatial localization in NMR spectroscopy in vivo. Ann. N. Y. Acad. Sci. 508, 333-348. http://dx.doi.org/10.1111/j.1749-6632.1987.tb32915.x.

Bovée, W., Canese, R., Decorps, M., Forssell-Aronsson, E., Le Fur, Y., Howe, F., Karlsen, O., Knijn, A., Kontaxis, G., Köel, H., McLean, M., Podo, F., Slotboom, J., Vikhoff, B., Ziegler, A., 1998. Absolute metabolite quantification by in vivo NMR spectroscopy: IV. Multicentre trial on MRSI localisation tests. Magn. Reson. Imaging 16, 1113-1125. http://dx.doi.org/10.1016/S0730-725X(98)00120-9.

Boy, F., Evans, C.J., Edden, R.A.E., Lawrence, A.D., Singh, K.D., Husain, M., Sumner, P., 2011. Dorsolateral prefrontal $\gamma$-aminobutyric acid in men predicts individual differences in rash impulsivity. Biol. Psychiatry 70, 866-872. http://dx.doi.org/ 10.1016/j.biopsych.2011.05.030.

Brix, M.K., Ersland, L., Hugdahl, K., Dwyer, G.E., Grüner, R., Noeske, R., Beyer, M.K., Craven, A.R., 2017. Within- and between-session reproducibility of GABA measurements with MR spectroscopy. J. Magn. Reson. Imaging. http://dx.doi.org/ 10.1002/jmri.25588.

Chan, K.L., Oeltzschner, G., Schär, M., Barker, P.B., Edden, R.A.E., 2017a. Spatial Hadamard encoding of J-edited spectroscopy using slice-selective editing pulses. NMR Biomed. 30, e3688. http://dx.doi.org/10.1002/nbm.3688.

Chan, K.L., Puts, N.A.J., Schär, M., Barker, P.B., Edden, R.A.E., 2016. HERMES: hadamard encoding and reconstruction of MEGA-edited spectroscopy. Magn. Reson. Med. 76, 11-19. http://dx.doi.org/10.1002/mrm.26233.

Chan, K.L., Saleh, M.G., Oeltzschner, G., Barker, P.B., Edden, R.A.E., 2017b. Simultaneous measurement of Aspartate, NAA, and NAAG using HERMES spectral editing at 3 Tesla. Neuroimage. http://dx.doi.org/10.1016/j.neuroimage.2017.04.043.

Chang, L., Lee, P.L., Yiannoutsos, C.T., Ernst, T., Marra, C.M., Richards, T., Kolson, D., Schifitto, G., Jarvik, J.G., Miller, E.N., Lenkinski, R., Gonzalez, G., Navia, B.A., 2004. A multicenter in vivo proton-MRS study of HIV-associated dementia and its relationship to age. Neuroimage 23, 1336-1347. http://dx.doi.org/10.1016/ j.neuroimage.2004.07.067.

De Beer, R., Barbiroli, B., Gobbi, G., Knijn, A., Kogel, H., Langenberger, K., Tkac, I., Topp, S., 1998. Absolute metabolite quantification by in vivo NMR spectroscopy: III. Multicentre ${ }^{1} \mathrm{H}$ MRS of the human brain addressed by one and the same data-analysis protocol. Magn. Reson. Imaging 16, 1107-1111. http://dx.doi.org/10.1016/S0730725X(98)00119-2.

Deelchand, D.K., Adanyeguh, I.M., Emir, U.E., Nguyen, T.-M., Valabregue, R., Henry, P.G., Mochel, F., Öz, G., 2015. Two-site reproducibility of cerebellar and brainstem neurochemical profiles with short-echo, single-voxel MRS at 3T. Magn. Reson. Med. 73, 1718-1725. http://dx.doi.org/10.1002/mrm.25295.

DiCiccio, T.J., Efron, B., 1996. Bootstrap confidence intervals. Stat. Sci. 11, 189-228. http://dx.doi.org/10.1214/ss/1032280214.

Donahue, M.J., Near, J., Blicher, J.U., Jezzard, P., 2010. Baseline GABA concentration and fMRI response. Neuroimage 53, 392-398. http://dx.doi.org/10.1016/ j.neuroimage.2010.07.017.

Drenthen, G.S., Barendse, E.M., Aldenkamp, A.P., van Veenendaal, T.M., Puts, N.A.J., Edden, R.A.E., Zinger, S., Thoonen, G., Hendriks, M.P.H., Kessels, R.P.C., Jansen, J.F.A., 2016. Altered neurotransmitter metabolism in adolescents with highfunctioning autism. Psychiatry Res. Neuroimaging 256, 44-49. http://dx.doi.org/ 10.1016/j.pscychresns.2016.09.007.

Edden, R.A.E., Barker, P.B., 2007. Spatial effects in the detection of $\gamma$-aminobutyric acid: improved sensitivity at high fields using inner volume saturation. Magn. Reson. Med. 58, 1276-1282. http://dx.doi.org/10.1002/mrm.21383.

Edden, R.A.E., Crocetti, D., Zhu, H., Gilbert, D.L., Mostofsky, S.H., 2012a. Reduced GABA concentration in attention-deficit/hyperactivity disorder. Arch. Gen. Psychiatry 69, 750-753. http://dx.doi.org/10.1001/archgenpsychiatry.2011.2280.

Edden, R.A.E., Intrapiromkul, J., Zhu, H., Cheng, Y., Barker, P.B., 2012b. Measuring $\mathrm{T}_{2}$ in vivo with j-difference editing: application to GABA at 3 Tesla. J. Magn. Reson. Imaging 35, 229-234. http://dx.doi.org/10.1002/jmri.22865.

Edden, R.A.E., Oeltzschner, G., Harris, A.D., Puts, N.A.J., Chan, K.L., Boer, V.O., Schär, M., Barker, P.B., 2016. Prospective frequency correction for macromolecule-suppressed GABA editing at 3T. J. Magn. Reson. Imaging 44, 1474-1482. http://dx.doi.org/ 10.1002/jmri.25304.

Edden, R.A.E., Puts, N.A.J., Barker, P.B., 2012c. Macromolecule-suppressed GABA-edited magnetic resonance spectroscopy at 3T. Magn. Reson. Med. 68, 657-661. http:// dx.doi.org/10.1002/mrm.24391.

Edden, R.A.E., Puts, N.A.J., Harris, A.D., Barker, P.B., Evans, C.J., 2014. Gannet: a batchprocessing tool for the quantitative analysis of gamma-aminobutyric acid-edited MR spectroscopy spectra. J. Magn. Reson. Imaging 40, 1445-1452. http://dx.doi.org/ 10.1002/jmri.24478.

Emir, U.E., Tuite, P.J., Öz, G., 2012. Elevated pontine and putamenal GABA levels in mildmoderate Parkinson disease detected by 7 Tesla proton MRS. PLoS One 7, e30918. http://dx.doi.org/10.1371/journal.pone.0030918.

Evans, C.J., McGonigle, D.J., Edden, R.A.E., 2010. Diurnal stability of $\gamma$-aminobutyric acid concentration in visual and sensorimotor cortex. J. Magn. Reson. Imaging 31 204-209. http://dx.doi.org/10.1002/jmri.21996.

Foerster, B.R., Callaghan, B.C., Petrou, M., Edden, R.A.E., Chenevert, T.L., Feldman, E.L., 2012. Decreased motor cortex $\gamma$-aminobutyric acid in amyotrophic 
lateral sclerosis. Neurology 78, 1596-1600. http://dx.doi.org/10.1212/ WNL.0b013e3182563b57.

Foerster, B.R., Pomper, M.G., Callaghan, B.C., Petrou, M., Edden, R.A.E., Mohamed, M.A., Welsh, R.C., Carlos, R.C., Barker, P.B., Feldman, E.L., 2013. An imbalance between excitatory and inhibitory neurotransmitters in amyotrophic lateral sclerosis revealed by use of 3-T proton magnetic resonance spectroscopy. JAMA Neurol. 70, 1009-1016. http://dx.doi.org/10.1001/jamaneurol.2013.234.

Fujihara, K., Narita, K., Suzuki, Y., Takei, Y., Suda, M., Tagawa, M., Ujita, K., Sakai, Y., Narumoto, J., Near, J., Fukuda, M., 2015. Relationship of $\gamma$-aminobutyric acid and glutamate+glutamine concentrations in the perigenual anterior cingulate cortex with performance of Cambridge Gambling Task. Neuroimage 109, 102-108. http:// dx.doi.org/10.1016/j.neuroimage.2015.01.014.

Gaetz, W., Bloy, L., Wang, D.J., Port, R.G., Blaskey, L., Levy, S.E., Roberts, T.P.L., 2014 GABA estimation in the brains of children on the autism spectrum: measurement precision and regional cortical variation. Neuroimage 86, 1-9. http://dx.doi.org/ 10.1016/j.neuroimage.2013.05.068.

García-Gómez, J.M., Luts, J., Julià-Sapé, M., Krooshof, P., Tortajada, S., Robledo, J.V., Melssen, W., Fuster-García, E., Olier, I., Postma, G., Monleón, D., Moreno-Torres, À. Pujol, J., Candiota, A.-P., Martínez-Bisbal, M.C., Suykens, J., Buydens, L., Celda, B. Van Huffel, S., Arús, C., Robles, M., 2009. Multiproject-multicenter evaluation of automatic brain tumor classification by magnetic resonance spectroscopy. Magn. Reson. Mater. Phys. Biol. Med. 22, 5-18. http://dx.doi.org/10.1007/s10334-008 0146-y.

Gasparovic, C., Song, T., Devier, D., Bockholt, H.J., Caprihan, A., Mullins, P.G., Posse, S., Jung, R.E., Morrison, L.A., 2006. Use of tissue water as a concentration reference fo proton spectroscopic imaging. Magn. Reson. Med. 55, 1219-1226. http://dx.doi.org/ $10.1002 / \mathrm{mrm} .20901$

Geramita, M., van der Veen, J.W., Barnett, A.S., Savostyanova, A.A., Shen, J., Weinberger, D.R., Marenco, S., 2011. Reproducibility of prefrontal $\gamma$-aminobutyric acid measurements with $J$-edited spectroscopy. NMR Biomed. 24, 1089-1098. http://dx.doi.org/10.1002/nbm.1662.

Goldstein, H., Browne, W., Rasbash, J., 2002. Partitioning variation in multilevel models Underst. Stat. 1, 223-231. http://dx.doi.org/10.1207/S15328031US0104 02.

Graveron-Demilly, D., 2014. Quantification in magnetic resonance spectroscopy based on semi-parametric approaches. Magn. Reson. Mater. Phys. Biol. Med. 27, 113-130. http://dx.doi.org/10.1007/s10334-013-0393-4.

Greenhouse, I., King, M., Noah, S., Maddock, R.J., Ivry, R.B., 2017. Individual differences in resting corticospinal excitability are correlated with reaction time and GABA content in motor cortex. J. Neurosci. 37, 2686-2696. http://dx.doi.org/10.1523/ JNEUROSCI.3129-16.2017.

Halekoh, U., Højsgaard, S., 2014. A Kenward-Roger approximation and parametric bootstrap methods for tests in linear mixed models - the R package pbkrtest. J. Stat Softw. 59, 1-32. http://dx.doi.org/10.18637/jss.v059.i09.

Harris, A.D., Glaubitz, B., Near, J., John Evans, C., Puts, N.A.J., Schmidt-Wilcke, T. Tegenthoff, M., Barker, P.B., Edden, R.A.E., 2014. Impact of frequency drift on gamma-aminobutyric acid-edited MR spectroscopy. Magn. Reson. Med. 72, 941-948. http://dx.doi.org/10.1002/mrm.25009.

Harris, A.D., Puts, N.A.J., Barker, P.B., Edden, R.A.E., 2015a. Spectral-editing measurements of GABA in the human brain with and without macromolecule suppression. Magn. Reson. Med. 74, 1523-1529. http://dx.doi.org/10.1002/ mrm.25549.

Harris, A.D., Puts, N.A.J., Edden, R.A.E., 2015b. Tissue correction for GABA-edited MRS considerations of voxel composition, tissue segmentation, and tissue relaxations. J. Magn. Reson. Imaging 42, 1431-1440. http://dx.doi.org/10.1002/jmri.24903.

Harris, A.D., Saleh, M.G., Edden, R.A.E., 2017. Edited ${ }^{1}$ H magnetic resonance spectroscopy in vivo: methods and metabolites. Magn. Reson. Med. 77, 1377-1389. http://dx.doi.org/10.1002/mrm.26619.

Hasler, G., van der Veen, J.W., Tumonis, T., Meyers, N., Shen, J., Drevets, W.C., 2007. Reduced prefrontal glutamate/glutamine and $\gamma$-aminobutyric acid levels in major depression determined using proton magnetic resonance spectroscopy. Arch. Gen Psychiatry 64, 193. http://dx.doi.org/10.1001/archpsyc.64.2.193.

Hayes, A.F., 2006. A primer on multilevel modeling. Hum. Commun. Res. 32, 385-410. http://dx.doi.org/10.1111/j.1468-2958.2006.00281.x.

Henry, P.-G., Dautry, C., Hantraye, P., Bloch, G., 2001. Brain GABA editing without macromolecule contamination. Magn. Reson. Med. 45, 517-520. http://dx.doi.org/ 10.1002/1522-2594(200103)45:3<517::AID-MRM1068>3.0.CO;2-6.

Hnilicová, P., Považan, M., Strasser, B., Andronesi, O.C., Gajdošík, M., Dydak, U., Ukropec, J., Dobrota, D., Trattnig, S., Bogner, W., 2016. Spatial variability and reproducibility of GABA-edited MEGA-LASER 3D-MRSI in the brain at $3 \mathrm{~T}$. NMR Biomed. 29, 1656-1665. http://dx.doi.org/10.1002/nbm.3613.

Hu, Y., Chen, X., Gu, H., Yang, Y., 2013. Resting-state glutamate and GABA concentrations predict task-induced deactivation in the default mode network. J. Neurosci. 33, 18566-18573. http://dx.doi.org/10.1523/JNEUROSCI.197313.2013.

Julià-Sapé, M., Acosta, D., Mier, M., Arùs, C., Watson, D., 2006. A multi-centre, webaccessible and quality control-checked database of in vivo MR spectra of brain tumour patients. Magn. Reson. Mater. Phys. Biol. Med. 19, 22-33. http://dx.doi.org/ 10.1007/s10334-005-0023-X

Kaiser, L.G., Young, K., Meyerhoff, D.J., Mueller, S.G., Matson, G.B., 2008. A detailed analysis of localized J-difference GABA editing: theoretical and experimental study at 4T. NMR Biomed. 21, 22-32. http://dx.doi.org/10.1002/nbm.1150.

Kanowski, M., Kaufmann, J., Braun, J., Bernarding, J., Tempelmann, C., 2004. Quantitation of simulated short echo time ${ }^{1} \mathrm{H}$ human brain spectra by LCModel and AMARES. Magn. Reson. Med. 51, 904-912. http://dx.doi.org/10.1002/mrm.20063.

Kapogiannis, D., Reiter, D.A., Willette, A.A., Mattson, M.P., 2013. Posteromedial cortex glutamate and GABA predict intrinsic functional connectivity of the default mode network. Neuroimage 64, 112-119. http://dx.doi.org/10.1016/ j.neuroimage.2012.09.029.

Keevil, S., Barbiroli, B., Brooks, J.C., Cady, E., Canese, R., Carlier, P., Collins, D., Gilligan, P., Gobbi, G., Hennig, J., Kügel, H., Leach, M., Metzler, D., Mlynárik, V., Moser, E., Newbold, M., Payne, G., Ring, P., Roberts, J., Rowland, I., Thiel, T., Tkác, I., Topp, S., Wittsack, H., Wylezinska, M., Zaniol, P., Henriksen, O., Podo, F., 1998. Absolute metabolite quantification by in vivo NMR spectroscopy: II. A multicentre trial of protocols for in vivo localised proton studies of human brain. Magn. Reson. Imaging 16, 1093-1106. http://dx.doi.org/10.1016/S0730-725X(98) 00118-0.

Kegeles, L.S., Mao, X., Stanford, A.D., Girgis, R., Ojeil, N., Xu, X., Gil, R., Slifstein, M., AbiDargham, A., Lisanby, S.H., Shungu, D.C., 2012. Elevated prefrontal cortex $\gamma$-aminobutyric acid and glutamate-glutamine levels in schizophrenia measured in vivo with proton magnetic resonance spectroscopy. Arch. Gen. Psychiatry 69, 449-459. http://dx.doi.org/10.1001/archgenpsychiatry.2011.1519.

Lange, T., Ko, C.-W., Lai, P.-H., Dacko, M., Tsai, S.-Y., Buechert, M., 2016. Simultaneous detection of valine and lactate using MEGA-PRESS editing in pyogenic brain abscess. NMR Biomed. 29, 1739-1747. http://dx.doi.org/10.1002/nbm.3660.

Lee, P.L., Yiannoutsos, C.T., Ernst, T., Chang, L., Marra, C.M., Jarvik, J.G., Richards, T.L., Kwok, E.W., Kolson, D.L., Simpson, D., Tang, C.Y., Schifitto, G., Ketonen, L.M., Meyerhoff, D.J., Lenkinski, R.E., Gonzalez, R.G., Navia, B.A., 2003. A multi-center ${ }^{1} \mathrm{H}$ MRS study of the AIDS dementia complex: validation and preliminary analysis. J. Magn. Reson. Imaging 17, 625-633. http://dx.doi.org/ 10.1002/jmri.10295.

Long, Z., Dyke, J.P., Ma, R., Huang, C.C., Louis, E.D., Dydak, U., 2015. Reproducibility and effect of tissue composition on cerebellar $\gamma$-aminobutyric acid (GABA) MRS in an elderly population. NMR Biomed. 28, 1315-1323. http://dx.doi.org/10.1002/ nbm.3381.

McCormick, D.A., 1989. GABA as an inhibitory neurotransmitter in human cerebral cortex. J. Neurophysiol. 62, 1018-1027.

Mescher, M., Merkle, H., Kirsch, J., Garwood, M., Gruetter, R., 1998. Simultaneous in vivo spectral editing and water suppression. NMR Biomed. 11, 266-272. http:// dx.doi.org/10.1002/(SICI)1099-1492(199810)11:6<266::AID-NBM530>3.0.CO;2-J.

Mikkelsen, M., Singh, K.D., Sumner, P., Evans, C.J., 2016a. Comparison of the repeatability of GABA-edited magnetic resonance spectroscopy with and without macromolecule suppression. Magn. Reson. Med. 75, 946-953. http://dx.doi.org/ $10.1002 / \mathrm{mrm} .25699$.

Mikkelsen, M., Singh, K.D., Brealy, J.A., Linden, D.E.J., Evans, C.J., 2016b. Quantification of $\gamma$-aminobutyric acid (GABA) in ${ }^{1} \mathrm{H}$ MRS volumes composed heterogeneously of grey and white matter. NMR Biomed. 29, 1644-1655. http://dx.doi.org/10.1002/ nbm.3622.

Mullins, P.G., McGonigle, D.J., O'Gorman, R.L., Puts, N.A.J., Vidyasagar, R., Evans, C.J., Cardiff Symposium on MRS of GABA, Edden, R.A.E., 2014. Current practice in the use of MEGA-PRESS spectroscopy for the detection of GABA. Neuroimage 86, 43-52. http://dx.doi.org/10.1016/j.neuroimage.2012.12.004.

Muthukumaraswamy, S.D., Edden, R.A.E., Jones, D.K., Swettenham, J.B., Singh, K.D., 2009. Resting GABA concentration predicts peak gamma frequency and fMRI amplitude in response to visual stimulation in humans. Proc. Natl. Acad. Sci. U. S. A. 106, 8356-8361. http://dx.doi.org/10.1073/pnas.0900728106.

Myers, J.F., Nutt, D.J., Lingford-Hughes, A.R., 2016. $\gamma$-aminobutyric acid as a metabolite: interpreting magnetic resonance spectroscopy experiments. J. Psychopharmacol. 30, 422-427. http://dx.doi.org/10.1177/0269881116639298.

Near, J., Andersson, J., Maron, E., Mekle, R., Gruetter, R., Cowen, P., Jezzard, P., 2013a. Unedited in vivo detection and quantification of $\gamma$-aminobutyric acid in the occipital cortex using short-TE MRS at 3 T. NMR Biomed. 26, 1353-1362. http://dx.doi.org/ $10.1002 / \mathrm{nbm} .2960$.

Near, J., Edden, R., Evans, C.J., Paquin, R., Harris, A., Jezzard, P., 2015. Frequency and phase drift correction of magnetic resonance spectroscopy data by spectral registration in the time domain. Magn. Reson. Med. 73, 44-50. http://dx.doi.org/ $10.1002 / \mathrm{mrm} .25094$.

Near, J., Evans, C.J., Puts, N.A.J., Barker, P.B., Edden, R.A.E., 2013b. J-difference editing of gamma-aminobutyric acid (GABA): simulated and experimental multiplet patterns. Magn. Reson. Med. 70, 1183-1191. http://dx.doi.org/10.1002/mrm.24572.

Near, J., Ho, Y.-C.L., Sandberg, K., Kumaragamage, C., Blicher, J.U., 2014. Long-term reproducibility of GABA magnetic resonance spectroscopy. Neuroimage 99, 191-196. http://dx.doi.org/10.1016/j.neuroimage.2014.05.059.

O'Gorman, R.L., Michels, L., Edden, R.A., Murdoch, J.B., Martin, E., 2011. In vivo detection of GABA and glutamate with MEGA-PRESS: reproducibility and gender effects. J. Magn. Reson. Imaging 33, 1262-1267. http://dx.doi.org/10.1002/ jmri.22520.

Oeltzschner, G., Puts, N.A.J., Chan, K.L., Boer, V.O., Barker, P.B., Edden, R.A.E., 2017 Dual-volume excitation and parallel reconstruction for J-difference-edited MR spectroscopy. Magn. Reson. Med. 77, 16-22. http://dx.doi.org/10.1002/mrm.26536.

Öngür, D., Prescot, A.P., McCarthy, J., Cohen, B.M., Renshaw, P.F., 2010. Elevated gamma-aminobutyric acid levels in chronic schizophrenia. Biol. Psychiatry 68, 667-670. http://dx.doi.org/10.1016/j.biopsych.2010.05.016.

Petrou, M., Pop-Busui, R., Foerster, B.R., Edden, R.A., Callaghan, B.C., Harte, S.E., Harris, R.E., Clauw, D.J., Feldman, E.L., 2012. Altered excitation-inhibition balance in the brain of patients with diabetic neuropathy. Acad. Radiol. 19, 607-612. http:// dx.doi.org/10.1016/j.acra.2012.02.004.

Peugh, J.L., 2010. A practical guide to multilevel modeling. J. Sch. Psychol. 48, 85-112. http://dx.doi.org/10.1016/j.jsp.2009.09.002.

Puts, N.A.J., Edden, R.A.E., 2012 Jan. In vivo magnetic resonance spectroscopy of GABA: a methodological review. Prog. Nucl. Magn. Reson. Spectrosc. 60, 29-41. http:// dx.doi.org/10.1016/j.pnmrs.2011.06.001. 
Puts, N.A.J., Edden, R.A.E., Evans, C.J., McGlone, F., McGonigle, D.J., 2011. Regionally specific human GABA concentration correlates with tactile discrimination thresholds. J. Neurosci. 31, 16556-16560. http://dx.doi.org/10.1523/JNEUROSCI.448911.2011.

Puts, N.A.J., Wodka, E.L., Harris, A.D., Crocetti, D., Tommerdahl, M., Mostofsky, S.H., Edden, R.A.E., 2016. Reduced GABA and altered somatosensory function in children with autism spectrum disorder. Autism Res. 1-12. http://dx.doi.org/10.1002/ aur.1691.

Price, R.B., Shungu, D.C., Mao, X., Nestadt, P., Kelly, C., Collins, K.A., Murrough, J.W., Charney, D.S., Mathew, S.J., 2009. Amino acid neurotransmitters assessed by proton magnetic resonance spectroscopy: relationship to treatment resistance in major depressive disorder. Biol. Psychiatry 65, 792-800. http://dx.doi.org/10.1016/ j.biopsych.2008.10.025.

R Core Team, 2017. R: a Language and Environment for Statistical Computing. R Foundation for Statistical Computing, Vienna, Austria. https://www.R-project.org.

Rae, C.D., 2014. A guide to the metabolic pathways and function of metabolites observed in human brain ${ }^{1} \mathrm{H}$ magnetic resonance spectra. Neurochem. Res. 39, 1-36. http:// dx.doi.org/10.1007/s11064-013-1199-5.

Rothman, D.L., Petroff, O.A., Behar, K.L., Mattson, R.H., 1993. Localized ${ }^{1} \mathrm{H}$ NMR measurements of $\gamma$-aminobutyric acid in human brain in vivo. Proc. Natl. Acad. Sci. U. S. A. 90, 5662-5666.

Rowland, L.M., Krause, B.W., Wijtenburg, S.A., McMahon, R.P., Chiappelli, J., Nugent, K.L., Nisonger, S.J., Korenic, S.A., Kochunov, P., Hong, L.E., 2016. Medial frontal GABA is lower in older schizophrenia: a MEGA-PRESS with macromolecule suppression study. Mol. Psychiatry 21, 198-204. http://dx.doi.org/10.1038/ mp.2015.34.

Sabati, M., Sheriff, S., Gu, M., Wei, J., Zhu, H., Barker, P.B., Spielman, D.M., Alger, J.R. Maudsley, A.A., 2015. Multivendor implementation and comparison of volumetric whole-brain echo-planar MR spectroscopic imaging. Magn. Reson. Med. 74, 1209-1220. http://dx.doi.org/10.1002/mrm.25510.

Sacktor, N., Skolasky, R.L., Ernst, T., Mao, X., Selnes, O., Pomper, M.G., Chang, L., Zhong, K., Shungu, D.C., Marder, K., Shibata, D., Schifitto, G., Bobo, L., Barker, P.B., 2005. A multicenter study of two magnetic resonance spectroscopy techniques in individuals with HIV dementia. J. Magn. Reson. Imaging 21, 325-333. http:// dx.doi.org/10.1002/jmri.20272.

Saleh, M.G., Oeltzschner, G., Chan, K.L., Puts, N.A.J., Mikkelsen, M., Schär, M., Harris, A.D., Edden, R.A.E., 2016. Simultaneous edited MRS of GABA and glutathione. Neuroimage 142, 576-582. http://dx.doi.org/10.1016/ j.neuroimage.2016.07.056.

Scheenen, T.W.J., Fütterer, J., Weiland, E., van Hecke, P., Lemort, M., Zechmann, C., Schlemmer, H.-P., Broome, D., Villeirs, G., Lu, J., Barentsz, J., Roell, S., Heerschap, A., 2011. Discriminating cancer from noncancer tissue in the prostate by 3-dimensional proton magnetic resonance spectroscopic imaging: a prospective multicenter validation study. Invest. Radiol. 46, 25-33. http://dx.doi.org/10.1097/ RLI.0b013e3181f54081.

Schielzeth, H., 2010. Simple means to improve the interpretability of regression coefficients. Methods Ecol. Evol. 1, 103-113. http://dx.doi.org/10.1111/j.2041210X.2010.00012.x.

Shibata, K., Sasaki, Y., Bang, J.W., Walsh, E.G., Machizawa, M.G., Tamaki, M., Chang, L.H., Watanabe, T., 2017. Overlearning hyperstabilizes a skill by rapidly making neurochemical processing inhibitory-dominant. Nat. Neurosci. 20, 470-475. http:// dx.doi.org/10.1038/nn.4490.

Shungu, D.C., Mao, X., Gonzales, R., Soones, T.N., Dyke, J.P., van der Veen, J.W., Kegeles, L.S., 2016. Brain $\gamma$-aminobutyric acid (GABA) detection in vivo with the $J$ editing ${ }^{1} \mathrm{H}$ MRS technique: a comprehensive methodological evaluation of sensitivity enhancement, macromolecule contamination and test-retest reliability. NMR Biomed. 29, 932-942. http://dx.doi.org/10.1002/nbm.3539.
Silveri, M.M., Sneider, J.T., Crowley, D.J., Covell, M.J., Acharya, D., Rosso, I.M., Jensen, J.E., 2013. Frontal lobe $\gamma$-aminobutyric acid levels during adolescence: associations with impulsivity and response inhibition. Biol. Psychiatry 74, 296-304. http://dx.doi.org/10.1016/j.biopsych.2013.01.033.

Snijders, T.A.B., Bosker, R.J., 2012. Multilevel Analysis: an Introduction to Basic and Advanced Multilevel Modeling. SAGE Publications, London.

Soher, B.J., Hurd, R.E., Sailasuta, N., Barker, P.B., 1996. Quantitation of automated single-voxel proton MRS using cerebral water as an internal reference. Magn. Reson. Med. 36, 335-339. http://dx.doi.org/10.1002/mrm.1910360302.

Stagg, C.J., Bachtiar, V., Johansen-Berg, H., 2011. What are we measuring with GABA magnetic resonance spectroscopy? Commun. Integr. Biol. 4, 573-575. http:// dx.doi.org/10.4161/cib.16213.

Star-Lack, J., Nelson, S.J., Kurhanewicz, J., Huang, L.R., Vigneron, D.B., 1997. Improved water and lipid suppression for 3D PRESS CSI using RF band selective inversion with gradient dephasing (BASING). Magn. Reson. Med. 38, 311-321. http://dx.doi.org/ 10.1002/mrm.1910380222.

Tate, A.R., Majós, C., Moreno, A., Howe, F.A., Griffiths, J.R., Arús, C., 2003. Automated classification of short echo time in in vivo ${ }^{1} \mathrm{H}$ brain tumor spectra: a multicenter study. Magn. Reson. Med. 49, 29-36. http://dx.doi.org/10.1002/mrm.10315.

Terpstra, M., Ugurbil, K., Gruetter, R., 2002. Direct in vivo measurement of human cerebral GABA concentration using MEGA-editing at 7 Tesla. Magn. Reson. Med. 47, 1009-1012. http://dx.doi.org/10.1002/mrm.10146.

Träber, F., Block, W., Freymann, N., Gür, O., Kucinski, T., Hammen, T., Ende, G., Pilatus, U., Hampel, H., Schild, H.H., Heun, R., Jessen, F., 2006. A multicenter reproducibility study of single-voxel ${ }^{1} \mathrm{H}$-MRS of the medial temporal lobe. Eur. Radiol. 16, 1096-1103. http://dx.doi.org/10.1007/s00330-005-0108-y.

van de Bank, B.L., Emir, U.E., Boer, V.O., van Asten, J.J.A., Maas, M.C., Wijnen, J.P. Kan, H.E., Oz, G., Klomp, D.W.J., Scheenen, T.W.J., 2015. Multi-center reproducibility of neurochemical profiles in the human brain at 7T. NMR Biomed. 28, 306-316. http://dx.doi.org/10.1002/nbm.3252.

Vicente, J., Fuster-Garcia, E., Tortajada, S., García-Gómez, J.M., Davies, N., Natarajan, K., Wilson, M., Grundy, R.G., Wesseling, P., Monleón, D., Celda, B., Robles, M., Peet, A.C., 2013. Accurate classification of childhood brain tumours by in vivo ${ }^{1} \mathrm{H}$ MRS - a multi-centre study. Eur. J. Cancer 49, 658-667. http://dx.doi.org/10.1016/ j.ejca.2012.09.003.

Waddell, K.W., Avison, M.J., Joers, J.M., Gore, J.C., 2007. A practical guide to robust detection of GABA in human brain by $J$-difference spectroscopy at $3 \mathrm{~T}$ using a standard volume coil. Magn. Reson. Imaging 25, 1032-1038. http://dx.doi.org/ 10.1016/j.mri.2006.11.026.

Wijnen, J.P., van Asten, J.J.A., Klomp, D.W.J., Sjobakk, T.E., Gribbestad, I.S., Scheenen, T.W.J., Heerschap, A., 2010. Short echo time ${ }^{1}$ H MRSI of the human brain at $3 \mathrm{~T}$ with adiabatic slice-selective refocusing pulses; reproducibility and variance in a dual center setting. J. Magn. Reson. Imaging 31, 61-70. http://dx.doi.org/ 10.1002/jmri.21999.

Yoon, J.H., Grandelis, A., Maddock, R.J., 2016. Dorsolateral prefrontal cortex GABA concentration in humans predicts working memory load processing capacity. J. Neurosci. 36, 11788-11794. http://dx.doi.org/10.1523/JNEUROSCI.197016.2016.

Yoon, J.H., Maddock, R.J., Rokem, A., Silver, M.A., Minzenberg, M.J., Ragland, J.D., Carter, C.S., 2010. GABA concentration is reduced in visual cortex in schizophrenia and correlates with orientation-specific surround suppression. J. Neurosci. 30, 3777-3781. http://dx.doi.org/10.1523/JNEUROSCI.6158-09.2010.

Zhu, H., Edden, R.A.E., Ouwerkerk, R., Barker, P.B., 2011. High resolution spectroscopic imaging of GABA at 3 Tesla. Magn. Reson. Med. 65, 603-609. http://dx.doi.org/ $10.1002 / \mathrm{mrm} .22671$ 